Review Article

\title{
Macrophage Activation and Functions during Helminth Infection: Recent Advances from the Laboratory Mouse
}

\author{
Marion Rolot and Benjamin G. Dewals $\mathbb{D}$ \\ Immunology-Vaccinology, Department of Infectious and Parasitic Diseases, Faculty of Veterinary Medicine-FARAH, \\ University of Liège, Liège, Belgium \\ Correspondence should be addressed to Benjamin G. Dewals; bgdewals@uliege.be
}

Received 17 March 2018; Accepted 23 May 2018; Published 2 July 2018

Academic Editor: Nicolas Gaudenzio

Copyright (C) 2018 Marion Rolot and Benjamin G. Dewals. This is an open access article distributed under the Creative Commons Attribution License, which permits unrestricted use, distribution, and reproduction in any medium, provided the original work is properly cited.

\begin{abstract}
Macrophages are highly plastic innate immune cells that adopt an important diversity of phenotypes in response to environmental cues. Helminth infections induce strong type 2 cell-mediated immune responses, characterized among other things by production of high levels of interleukin- (IL-) 4 and IL-13. Alternative activation of macrophages by IL-4 in vitro was described as an opposite phenotype of classically activated macrophages, but the in vivo reality is much more complex. Their exact activation state as well as the role of these cells and associated molecules in type 2 immune responses remains to be fully understood. We can take advantage of a variety of helminth models available, each of which have their own feature including life cycle, site of infection, or pathological mechanisms influencing macrophage biology. Here, we reviewed the recent advances from the laboratory mouse about macrophage origin, polarization, activation, and effector functions during parasitic helminth infection.
\end{abstract}

\section{Introduction}

Parasitic helminths infect the majority of vertebrates [1]. Although parasitic helminths are near to absent in northwestern countries in humans, they are still responsible for infecting more than a quarter of the human population, essentially afflicting people who live in areas of poverty in the developing world [2], and they are also heavily present in domestic animals of veterinary importance [3]. In humans, 1.5 billion people are infected with soiltransmitted helminths (or intestinal nematodes) that persist in the intestine as adult worms for a prolonged period of time [4], filarial nematodes are tissue-dwelling parasites of more than 150 million people [5], while blood flukes (schistosomes) infect about 240 million people worldwide and induce chronic systemic and liver disease [6]. In addition, infection with larval stages of Taeniids remains an important zoonotic problem.

Helminths have evolved to adapt to the host they infect and developed immune evasion strategies that have in return shaped the immune system of the infected host. Such evolution may be explained by different phenomena, the most evident being that many helminths undertake specific multiorgan migratory trajectories before reaching their final destination such as the lung, intestine, liver, or blood vessels where they can persist and cause chronic infections. Helminths must also ensure that their offspring will find their way out without being stopped by the host immune system [7]. These often-complex life cycles have lead helminths to develop mechanisms to invade and migrate through the host while modulating the immune system and ensure their long-lasting persistence in their host [8]. As an example, the intestinal nematode Heligmosomoides polygyrus produces a TGF- $\beta$ mimic during its invasive stages causing the induction of regulatory $\mathrm{T}$ cells (Tregs) in mice [9], a $\mathrm{T}$ cell subset that controls immunity in infection, allergy, and autoimmunity [10]. Besides, appropriate immune response is needed to repair tissue damage linked to parasite migration or to avoid damage caused by excessive immune activation. Therefore, immune modulatory mechanisms like 
induction of Tregs highlight the fact that these parasites are shaping the host immune system to reach a wellbalanced tradeoff between immune evasion for parasite persistence and the modulation of host tissue damage to reduce as much as possible deleterious effects of worm persistence.

Parasitic helminths generally induce strong type 2 immunity that normally controls parasite infection and is characterized by production of type 2 cytokines like interleukin- (IL-) 4, IL-5, and IL-13 by innate cells (group 2 innate lymphoid cells (ILC2s), basophils, eosinophils, neutrophils, and macrophages) and $\mathrm{CD} 4^{+} \mathrm{T}$ helper 2 (Th2) lymphocytes. Type 2 cell-mediated immunity is a general feature of helminth infection regardless of the multivariate sites of colonization of the numerous helminth species [11] and is conserved from jawed fish to mammals [7]. Studies on mouse models of helminth infections have provided essential findings towards understanding type 2 immunity induction as well as its effector functions [12]. An important aspect about type 2 cell-mediated responses against parasitic helminths is that they are induced for controlling parasite infection but they also mediate the tolerance of parasite persistence [1]. In a number of cases, effector responses induced during type 2 immune responses promote the expulsion of intestinal helminths and prevent reinfection. Although type 2 immune responses developed in infected patients are not always sufficient to prevent disease, the induction of such responses aim to keeping parasite burdens under levels potentially resulting in pathologic sequelae (anaemia, growth retardation, fibrosis, etc.) that can be severely detrimental at the individual level and significantly delay socioeconomic development at the population level [13]. Besides promoting resistance to high-burden helminth infection, type 2 immune responses also include modulation/resolution of proinflammatory responses and tissue repair without directly affecting worm persistence [14]. Interestingly, Th2 cells in the liver ensure appropriate development of schistosome worms, further highlighting coevolution of the parasite and its host [15]. Thus, such tolerance mechanisms would permit low number of worms to persist while avoiding immunopathology. Coevolution of lowburden parasitic helminths with their respective host would be encouraged and could even lead, in some settings, to a mutually beneficial relationship of the host and parasite. Indeed, low-burden chronic infections with helminths are mostly asymptomatic and have demonstrated to be benefic to other diseases, especially in the case of autoimmunity and allergy $[16,17]$ as well as obesity or even autism [18], which advocates the use of specific helminths or derived products as therapeutic strategies while encouraging guided deworming campaigns [19].

Among type 2 cell-mediated mechanisms involved in the response against parasitic helminths, polarization of macrophages and their effector functions in host protection has been thoroughly studied. In this review, we will focus on the recent advances from the mouse model that lead our understanding on the roles of macrophages during parasitic helminth infection and discuss the challenges and opportunities in the future.

\section{Macrophage Activation and Helminth Infection}

Since their initial description by Élie Metchnikoff as immune cells mediating phagocytosis [20], we now know that macrophage function is not restricted to simply engulfing unicellular pathogens such as bacteria and protozoa but represents a large and heterogeneous family of cell subsets displaying different functions in physiological and pathological processes. Hence, macrophages are innate cells that can destroy pathogens but also clear apoptotic cell bodies and regulate the host immune response [21]. The functions of macrophages depend on their mode of activation that leads to their "polarization" towards effector functions. The activation of macrophages after infection by pathogens is mediated by pathogen-associated molecular patterns (PAMPs) and cytokines. For over 20 years, macrophages have been dichotomized in two main activation phenotypes that were essentially based on in vitro work on murine macrophages. Classically activated macrophages (CAMs, also known as M1) are instructed by bacterial products (LPS) and interferon- (IFN-) $\gamma$ produced during type 1 immune responses and develop strong intracellular-killing nitric oxide (NO) in mice [21]. As opposed to classical macrophage activation, the work of Siamon Gordon in the 1990s highligted that macrophages could be alternatively activated by IL-4 [22] with increased mannose receptor (CD206), cellular responses associated with tissue repair, and reduced antimicrobial nitric oxide synthase (iNOS) production. Several molecules describing classical and alternative activation of macrophages in mice do not have an equivalent in humans. Recent work has aimed to provide a similar dichotomy in human macrophages [23-26]. Since the description of alternatively activated macrophages (AAMs, also known as M2), it now appears that macrophage activation cannot simply be subdivided in M1 and M2 subsets. Indeed, macrophages are not necessarily equals in terms of tissue origin or differentiation, and depending on the cytokine and toll-like receptor (TLR) agonists involved, these cells can exert an array of various levels of activation patterns going from two extremes: IFN- $\gamma$-activated [M (IFN- $\gamma$ )] or IL-4-activated [M (IL-4)] macrophages [27]. Thus, defining classical versus alternative macrophage activation is not perfect to genuinely describe the complexity of polarization of the activation status of macrophage subsets in inflammatory and homeostatic settings at a given point in time and space. Nonetheless, efforts to further decode polarization in the era of single-cell sequencing and linking it to the actual functions of macrophage polarization are advancing [27-29].

AAMs are defined by their response to IL- 4 and/or IL-13, two cytokines that signal through the IL- 4 receptor $\alpha$ chain (IL-4R $\alpha$ ) (Figure 1). IL-4R $\alpha$ heterodimerizes with the common $\gamma$-chain $(\gamma \mathrm{c})$ or IL-13R $\alpha 1$ to form the type I or type II receptor, respectively. Whereas IL-4 signals through both receptors, IL-13 only binds the type II receptor. Tissue colonization by helminths induces the rapid release of type 2 cytokines like IL- 4 and IL-13 by ILC2s, eosinophils, neutrophils, basophils, or NKT cells (and at a later time point Th2 cells) that will instruct macrophages to adopt a phenotype 


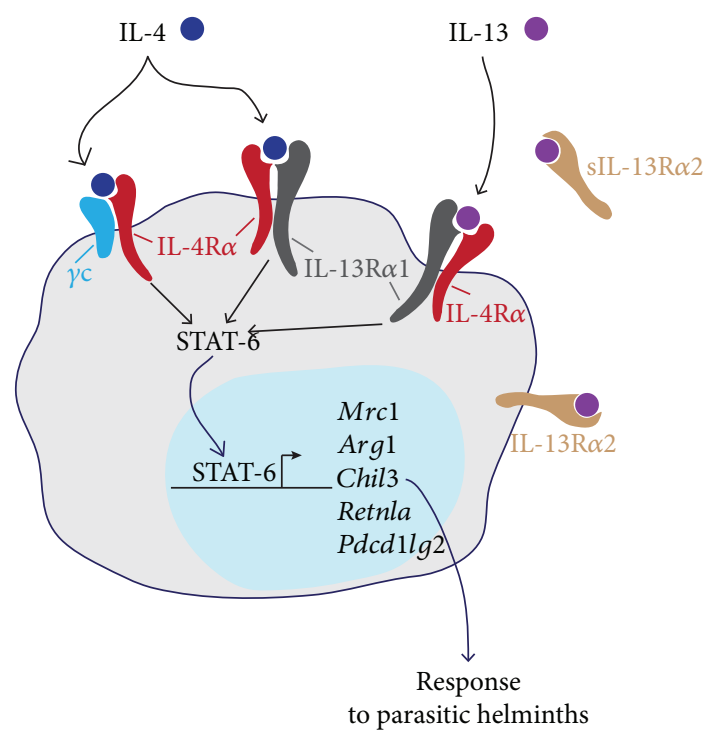

FIGURE 1: IL-4R $\alpha$-dependent alternative macrophage activation during helminth infection. Type 2 innate and adaptive immune cells produce the cytokines IL- 4 and IL-13 after exposure to parasitic helminths. In the laboratory mouse, these cytokines induce AAMs which are characterized by the upregulation of signature genes. IL-4R $\alpha$ : IL-4 receptor alpha chain; $\gamma$ c: common gamma chain; IL-13R $\alpha 1$ : IL-13 receptor alpha 1 chain; IL-13R $\alpha 2$ : IL-13 receptor alpha 2 chain (sIL-13R $\alpha 2$, secreted form); STAT6: signal transducer and activator of transcription 6; Mrc1: mannose receptor (CD206); Arg1: arginase 1; Chil3: chitinase-like 3 (Ym1); Retnla: resistin-like molecule alpha (Relm- $\alpha$ ), Pdcd1lg2: programmed cell death 1 ligand 2 (PD-L2).

close the AAM polarization observed by Gordon and Martinez [30]. In the rest of this review, we will refer to AAMs when describing helminth-induced IL-4/13dependent activation of macrophages. Of note, additional cytokines have been shown to contribute to AAM polarization. IL-21 promotes the expression of IL-4R $\alpha$ and IL$13 \mathrm{R} \alpha 1$ on macrophages [31], whereas IL-33 can signal through its T1/ST2 receptor on macrophages and drive an AAM phenotype together while triggering ILC2s and Th2 cells to promote IL- 4 and IL-13 production [32, 33]. Besides, it has been convincingly reported that protective mechanism and tissue repair against $H$. polygyrus is further mediated by IgG-dependent induction of Arg1 in AAMs, independently of IL-4R $\alpha$ [34-36], and that surfactant protein D directly interacts with L4 larvae of Nippostrongylus brasiliensis and lung macrophages to promote their polarization into AAMs in the lung and contribute to controlling helminth infection [37]. Thus, activation of macrophages during helminth infection is not restricted to the simplified view of M (IL-4) polarized macrophages.

Tissue damage caused by helminth tissue colonization induces the release of alarmins such as IL-33 and IL-25 that leads to the activation of innate cells like ILC2s and the production of large amounts of IL-13, IL-5, and IL-4. Tissue alteration therefore indirectly leads to AAM polarization, and a recent report has shown that macrophages also need to directly respond to such alteration of the tissue by phosphatidylserin-mediated phagocytosis of apoptotic cells together with IL-4 and IL-13 signaling [38]. Interestingly, necroptosis in the liver after Listeria monocytogenes infection led to IL-4 release by basophils for AAM polarization of recruited monocytes in the liver for tissue repair [39].

The metabolism of arginine is a keystone that distinguishes AAMs from CAMs [21]. iNOS induced in CAMs after IFN- $\gamma$ and bacterial PAMP activation metabolizes arginine to produce antimicrobial molecules like nitric oxide and citrulline. In AAMs, iNOS levels are reduced but arginase-1 (Arg1) expression increases. Arg1 hydrolyzes arginine in ornithine and urea. Because ornithine can be metabolized in proline (required for collagen deposition), AAM-derived Arg1 has long been regarded as essential for fibrosis and wound healing. However, work by Pesce and colleagues suggests rather that Arg1 in AAMs deplete arginine from the extracellular space for restraining $\mathrm{T}$ cell function by amino acid starvation than promoting fibrosis [40]. The latter hypothesis was further supported by the observation that hepatic stellate cells rather than Küpffer cells drive liver fibrosis after Schistosoma mansoni infection [41, 42]. Nonetheless, AAMs could still have healing capacities but not directly dependent on Arg1 activation [43, 44]. Instead, Esser-von Bieren and colleagues highlighted a role for ornithine in immobilizing $H$. polygyrus larvae after secondary infection [34]. Additional functions of AAM-dependent Arg1/ornithine may are still to be unraveled.

\section{The Activation and Functions of AAMs after Infection with Helminths: Advances from Experimental Infection Models}

3.1. Nematode Infections. Several groups have used nematode models in mice and demonstrated important functions of AAMs in helminth infection. In particular, studies involving intestinal $H$. polygyrus [45] and $N$. brasiliensis nematodes as well as filarial nematodes like Brugia malayi highlighted how induction of AAMs is determinant in the response against these parasites.

H. polygyrus (previously termed Nematospiroides dubius) is the dominant intestinal nematode of the European wood mouse [45], and its adaptation to the laboratory mouse has led to the suggestion to rename the adapted strain as $H$. bakeri. Nonetheless, additional data is still necessary to plainly justify the change in nomenclature [46]. H. polygyrus belongs to the order Strongylida, as the human hookworm parasites, and to the superfamily Trichostrongyloidea, as the ruminant parasites Haemonchus contortus and Teladorsagia circumcincta. $H$. polygyrus is an appropriate model of these chronic helminthiases, as primary infections can persist for many months in the intestine of susceptible strains of mice. Importantly, its life cycle is contained in the intestine which excludes potential confounding responses from the multiorgan migration observed for other nematode species, and its susceptibility to anthelminthic drugs like mebendazole renders studies on recall responses available. $H$. polygyrus infection induced AAMs in the intestine, and rapid resolution of reinfection with $H$. polygyrus has been shown to be 


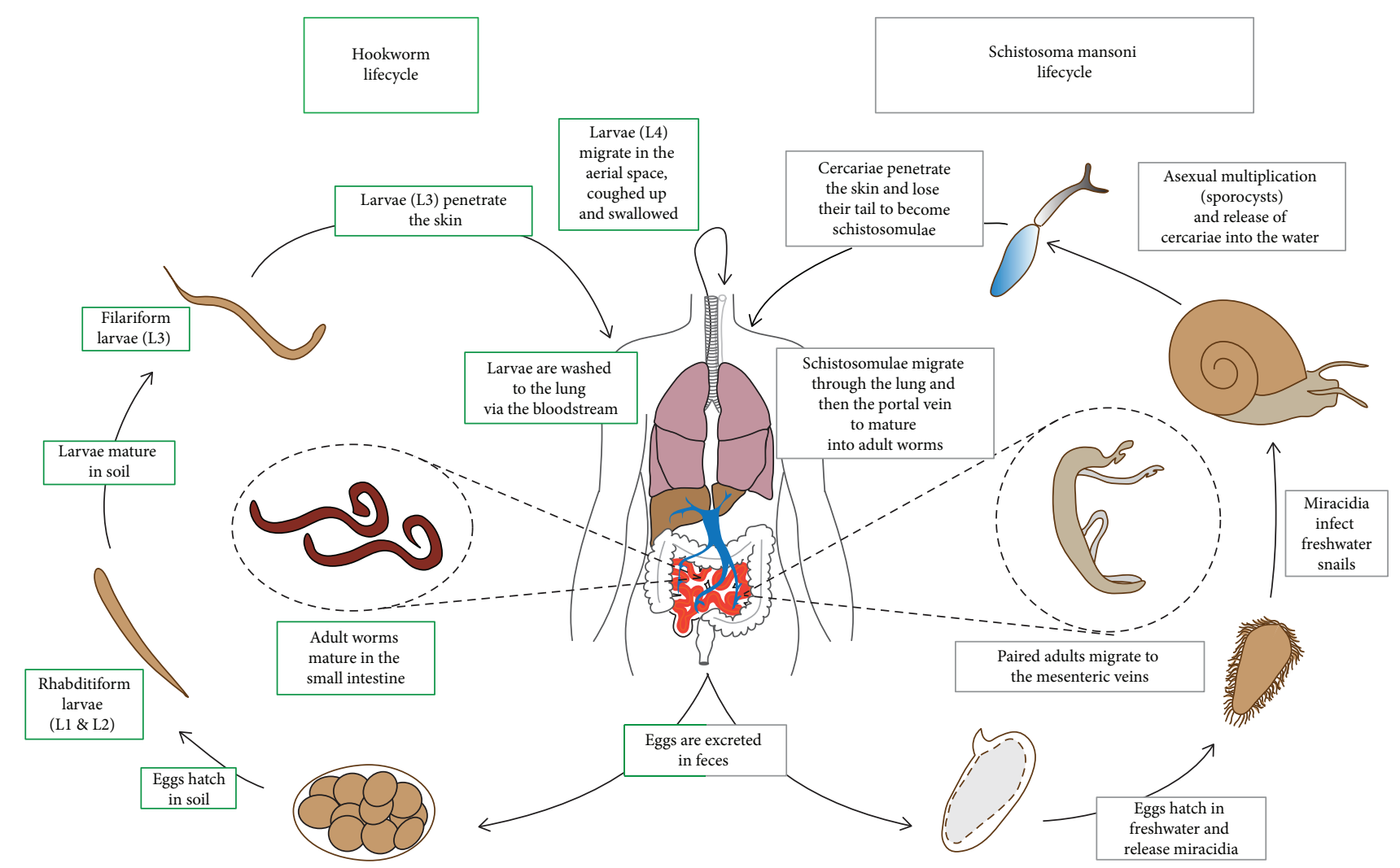

Figure 2: Graphical representation of the life cycles of hookworms (human: Necator americanus or Ancylostoma duodenale; mouse: Nippostrongylus brasiliensis) and Schistosoma mansoni.

dependent on Arg1 and intestinal AAMs [47, 48]. However, AAM induction after $H$. polygyrus infection resulted in increased susceptibility to bacterial infection with reduced bactericidal activities and colitis exacerbation [49]. In the same line, infection with $H$. polygyrus or treatment with IL-4 and anti-IFN- $\gamma$ increased reactivation of a gammaherpesvirus from latently infected AAMs in C57BL/6 mice [50], suggesting alternative macrophage activation can have detrimental bystander effects.

N. brasiliensis (previously termed Heligmosomum muris and Nippostrongylus muris) is a nematode that naturally infects rats. Like $H$. polygyrus, $N$. brasiliensis belongs to the order Strongylida, as the human hookworm parasites Necator americanus or Ancylostoma duodenale. Albeit not directly related phylogenetically to human hookworms, $N$. brasiliensis has a very similar life cycle and is extensively used to investigate the host response to infection in the laboratory mouse. Free-living larvae invade the host percutaneously and enter the circulatory system, from where the larvae reach the lungs. Here, worms molt and breach the alveoli to reach the airway where they are coughed up, swallowed, and mature into adult worms in the intestinal lumen [51] (Figure 2). Infection of laboratory Balb/c or C57BL/6 mice induces strong type 2 cell-mediated responses that result in clearance of intestinal worms within 6-9 days after infection. IL-4 and IL-13 production after $N$. brasiliensis colonization of the host induces AAMs in the lung and the intestine $[52,53]$. Intestinal macrophages after $N$. brasiliensis infection upregulate signature proteins of
AAMs and depletion of intestinal macrophages by clodronate liposome treatment resulted in impaired expulsion of the nematode and affected smooth muscle contractility, partially involving Arg1 [53]. Thus, AAMs could contribute to the movement of luminal worms along the intestine collectively referred to as the "weep and sweep" mechanism, with increased intestinal contractility and mucous production. Whether or not the AAM presence seems to be essential for parasite clearance, their activation via the IL- $4 \mathrm{R} \alpha$ is not essential for resolving infection as observed in conditional knockout mice in macrophages for this receptor [54]. More work should focus on intestinal macrophages in parasite clearance to better define whether their role in promoting the weep and sweep is due to their alternative activation or whether it is just their presence as macrophages independently of their activation by IL-4 and IL-13.

$N$. brasiliensis larvae migrate through the lung and cause severe pulmonary pathology to the infected host, with hemorrhages that quickly resolve. Passage of larvae through the lung can result in a pathology initially analogous to allergic asthma that later develops in an emphysema-like disease [55-57]. Even though N. brasiliensis is responsible for fundamental changes in lung macrophage phenotypes with signatures of AAMs [52], a direct effect of lung AAMs on the regulation of parasite control remains unclear [58]. However, lung macrophages have been shown to contribute to resolving IL-17-driven inflammation and tissue damage in the lung after N. brasiliensis infection [59], and neutrophil response to the parasite appears to condition long-lived 
macrophages in the lung for controlling the nematode infection [60]. These results indicate that AAMs are key components to mediate control parasite infection in the lung and tissue repair, but it remains uncertain whether alternative activation via signaling through IL-4R $\alpha$ is truly essential.

Mouse infection with Brugia malayi (a filarial nematode that belongs to the order Spirurida, superfamily Filarioidea) also induces AAMs that strongly suppress $\mathrm{T}$ cell proliferation and have tissue repair functions $[61,62]$. B. malayi-induced AAMs could be reprogrammed to kill bacteria [63] and displayed elevated gene expression for arachidonic acid metabolism pathways, resulting in increased levels of PGI2 and PPAR $\gamma$-mediated activation [64]. Recent data further showed that AAMs induced after B. malayi infection sustained eosinophil immunity via CCR3 [65]. Macrophage activation after $B$. malayi infection was controlled by the induction via IL-4 of the microRNA miR-378-3p that downregulated the PI3K/Akt-signaling pathway [66], illustrating a self-control mechanism that limits AAM activation and expansion during type 2 inflammatory settings.

Overall, we can conclude that while macrophages are key players in the clearance of nematodes from the infected host, signaling through IL- $4 \mathrm{R} \alpha$ is also essential for resistance to nematode infection via induction of type 2 cell-mediated immune responses but not necessarily through induction of AAMs.

3.2. Trematode Infections. A few studies investigated on the role of AAMs after liver fluke (Fasciola hepatica) infection $[67,68]$. Although little is known on the role of AAMs during $F$. hepatica infection, a recent study showed that macrophage PD-L2 regulates type 1 immunity after infection [69], suggesting AAMs have regulatory functions.

The functions of AAMs after parasitic helminth infection have extensively been studied in mouse models of schistosomiasis-also known as bilharzia. Schistosoma mansoni, S. haematobium, and S. japonicum are the three main parasitic helminths responsible for human schistosomiasis and belong to the class Trematoda and the subfamily Schistosomatidae. Whereas S. mansoni and S. haematobium are found in Africa and the Middle East, S. mansoni is also found in Central and South America. S. japonicum infects people living in Asia, mainly in China and the Philippines [70]. Additional species can also be found in more localized areas. While S. mansoni, S. japonicum, S. mekongi, and S. guineensis are responsible for intestinal schistosomiasis, S. haematobium causes urogenital disease. The life cycle of the different species of schistosomes is similar and involves an intermediate freshwater snail host. The adult worms (males and females) live in the mesenteric veins of the infected host, where they mate and produce eggs. Each female worm can produce between 100 and 300 eggs per day and about half of them are excreted through faeces (S. mansoni and $S$. japonicum) or urine (S. haematobium). The other half of the produced eggs are trapped in host tissues such as the liver, intestine, or bladder, where they induce inflammation. Inflammation and tissue damage and remodeling elicited in reaction to parasite eggs are responsible for the main clinical signs including diarrhea, hematochezia, hepatomegaly, splenomegaly, ascite, or hematuria [70]. The eggs that reach freshwater will hatch and release free-living miracidia that infect a suitable intermediate snail host (Biomphalaria sp., Bulinus sp., or Oncomelania sp.). In the snail, the parasite then undergoes asexual replication through sporocyst stages during 4 to 6 weeks before shedding thousands of infectious cercariae into the water. The cercariae infect their mammalian host percutaneously, lose their tail, and migrate via the blood circulation to the lung where the maturing schistosomulae will become an adult worm that migrates to the liver veins and mesenteric venules. The parasite needs about 4-6 weeks before becoming mature adults and producing eggs (Figure 2).

Migration of the parasite through the host induces an immune reaction that differs depending on the stage of the life cycle, but despite repeated exposure, the immune response is not effective to prevent reinfection or clear parasites from the host. The direct consequence in areas where the prevalence of the parasite is high is the development of chronic disease.

S. mansoni infection of the laboratory mouse is well described and used as a model for human pathology [71, 72]. During the first weeks of infection, adult worms elicit an IFN- $\gamma$-dominated response. This response is then modulated by the arrival of the parasite eggs provoking a strong but not exclusive type 2 cell-mediated response that peaks around 7 to 8 weeks postinfection ("acute" phase) before being downregulated during the "chronic" phase by week 12 [73-76]. Type 2-dominated responses orchestrate the dynamic of the formation and maturation of inflammatory granulomas that is essential for protecting the host cells such as hepatocytes from cytotoxins produced by the eggs during the acute phase and then to heal the scar left by the dying eggs in the chronic phase [77]. These granulomas are mainly composed of $\mathrm{CD} 4^{+} \mathrm{T}$ lymphocytes, eosinophils, and AAMs [77]. Although macrophages and more particularly AAMs may play important roles in the induction of effective granulomatous response, much is needed to fully decipher their implication in the protective immune response against schistosomiasis [41, 78]. Unlike in nematode infection, protection against $S$. mansoni infection is not assessed by the efficiency of parasite expulsion. Indeed, susceptibility to $S$. mansoni is directly dependent on the host's ability to control egg-induced inflammation rather than directly controlling the number of blood-dwelling adult worms $[40,79,80]$. Current understanding of the control of egginduced inflammation depends on the acute or chronic phase of infection.

Metabolically active and harmful eggs are retained in the host tissue during the acute phase and induce a granulomatous inflammatory response to wall them off from the host tissue. Early studies have shown that type 2 immunity is mainly protective against murine schistosomiasis during the acute phase, corresponding to the peak of egg production. Indeed, mice deficient for IL-4, IL-13, IL-4/13, IL-4/10, or IL-4R $\alpha$ all develop severe intestinal and liver pathology to acute $S$. mansoni infection and rapidly die of the infection [54, 79, 81-85]. In 2004, Herbert and collaborators studied S. mansoni infection in $\mathrm{Lyz}^{\text {cre }} I l 4 \mathrm{ra}^{-/ l o x}$ mice, knockdown 
for the IL- $4 \mathrm{R} \alpha$ chain specifically in lysozyme M-expressing macrophages and neutrophils [54]. The authors reported that $L y z 2^{\text {cre }} I l 4 \mathrm{ra}^{-/ l o x}$ mice suffered an acute wasting disease similar to $I_{4} \mathrm{ra}^{-/-}$mice, with evidence of hepatotoxicity and endotoxemia. Although these results suggested a central role of AAMs in the susceptibility to acute schistosomiasis, it may not be so clear. Conflicting results using low and high doses of infection recently rather suggested that $\mathrm{Lyz}^{\text {cre }} \mathrm{Il} 4 \mathrm{ra}^{-1 / o x}$ mice are not highly susceptible to $S$. mansoni infection [80]. Indeed, Vannella and colleagues highlighted an incomplete deletion of IL-4R $\alpha$ among the heterogeneous macrophage populations of $S$. mansoni-infected $\mathrm{Lyz}^{\text {cre }} \mathrm{Il4 \textrm {ra } ^ { - / l o x }}$ mice. They observed an insufficient expression of $L y z 2$ (encoding lysozyme $\mathrm{M}$ ), therefore of cre-recombinase, in newly recruited, immature $\mathrm{F} 4 / 80^{\mathrm{hi}} \mathrm{CD} 11 \mathrm{~b}{ }^{\text {hi }}$ macrophages which retained features of alternative activation. Interestingly, these data further provide an alternate explanation to the presence of IL-10-dependent Ym1- and CD206-expressing macrophages in the granulomas of $\mathrm{Lyz}^{\mathrm{cre}} \mathrm{IlAra}^{-/ l o x}$ mice [86]. Moreover, two recent studies demonstrated that AAMs in the liver after $S$. mansoni infection resulted from the maturation of recruited Ly6C $\mathrm{C}^{\text {hi }}$ monocytes $[87,88]$. Thus, AAMs' protective roles during acute schistosomiasis and control of intestinal permeability remain unclear and further urge the development of new tools to investigate the functions of AAMs during in schistosomiasis. Table 1 summarizes the tools currently used or that could help understand macrophage functions in this context. As mentioned in the introduction, identification over the course of the infection of the range of macrophage polarizations in the liver and intestine should lead us towards novel mechanisms to better understand the true implication of AAMs in protection against egg-induced inflammation in acute schistosomiasis.

Liver fibrosis develops in the chronic phase of schistosomiasis. Although protective during the acute phase of the infection, type 2 inflammation can be detrimental during the chronic phase of infection with larger liver granulomas and increased collagen deposition, leading to portal hypertension, portosystemic venous shunts, and gastrointestinal hemorrhages. Using mice deficient for IL-13R $\alpha 1$ (type II receptor) or secreted decoy receptor IL-13R $\alpha 2$, it became clear that excess IL-13 is directly responsible for induction of collagen deposition and fibrosis, whereas both IL-4 and IL-13 mediate the inflammatory phenotype of egg-induced granulomas. Indeed, despite elevated levels of AAM gene signature expression in the liver, reduced fibrosis developed in Ill3 $\mathrm{ral}^{-1-}$ mice in response to S. mansoni infection [89]. In addition, neutralization of IL-13 by injection of a decoy receptor (sIL-13R $\alpha 2$ ) attenuated S. mansoniinduced liver fibrosis to a greater extent than suppression of IL-4 [90]. As mentioned above, although initially thought to promote collagen deposition via elevated levels of Arg1 expression, Pesce and collaborators showed that AAM-specific Arg1 reduces fibrosis rather than promotes it [40]. Using $L y z 2^{\text {cre }} A r g 1^{\text {lox/lox }}$ or $\mathrm{Tie} 2^{\text {cre }} A r g 1^{\text {lox/lox }}$ mice, they observed elevated fibrosis, increased granuloma volumes, and lower survival rate in the chronic phase of schistosomiasis. Interestingly, the idea that AAMs modulate type 2 immunity and fibrosis during chronic schistosomiasis was further supported by studies using mice deficient for resistin-like molecule $\alpha$ (Relm- $\alpha$ ) that developed increased type 2 immune responses as well as increased fibrosis and hepatosplenic pathology [58]. To add a level of complexity, increased granulomatous inflammation but no impact on the levels of fibrosis were observed in $\mathrm{Lyz}^{\mathrm{cre}} \mathrm{Il} 4 \mathrm{ra}{ }^{- \text {llox }}$ mice during the chronic stage of infection suggesting that there might be distinct subsets of AAMs in the liver after infection, as suggested above [80].

Overall, although their roles in tissue repair and survival during the acute phase of $S$. mansoni infection have yet to be clarified, AAMs or AAM-associated molecules were shown to be implicated in the control of excessive inflammation and in wound healing through regulation of IL-13-induced fibrosis.

3.3. Cestode Infections. The class Cestoda includes important zoonotic parasites of the family Taeniidae like Echinococcus sp. or Taenia sp. These segmented worms are characterized by an indirect life cycle with production of encysted larvae (metacestode) in intermediate host tissues and transmission to the final host via feeding on infected tissues. T. solium, E. granulosus, and E. multilocularis were ranked as the top 3 food-borne parasites based on multiple criteria including incidence, disease severity, or trade relevance and are therefore subject to both human and veterinary medical challenges [91]. Unlike other helminths, cestode infections remain an important concern in developed countries, probably due to the important public health risk and difficulty of treatment. Furthermore, prevalence of E. multilocularis reaches more than $10 \%$ in foxes of the most affected European countries like Estonia, Latvia, Lithuania, France, Switzerland, or Germany [92]. Associated pathologies are mostly linked to larval cystic stages inducing loss of function of the organ involved. Mice model for cestode infections includes intraperitoneal or intracranial injection of metacestodes from Mesocestoides corti [93-95] or T. crassiceps [95] (both related to $T$. solium), injection of protoscoleces extracted from $E$. multilocularis or E. granulosus hydatid cyst [96], or infection with eggs or metacestodes from Hymenolepis diminuta and H. nana $[97,98]$. The particularity of some Taeniid metacestodes to reproduce asexually is used in biological models. For instance, T. crassiceps larvae injected into the peritoneal cavity cause long-lasting infection and reproduce through outward budding. Nonetheless, metacestodes are usually sessile and grow in a fixed tissue site once established, leading to the development of various form of cysts depending on the species. The development of granulomatous immune responses against larval stages of cestode infections has been recently and extensively reviewed [99].

The role of macrophages in cestode infection is understudied, but interesting information comes from work on $T$. crassiceps. After $T$. crassiceps infection, an early type 1 immune response at the site of infection is shifted to a mix type $1 /$ type 2 response with production of both IFN- $\gamma$ and IL-4 $[100,101]$. Control of T. crassiceps infection is strikingly different from that of other nematodes or trematodes with initial protective type 1 immune responses that control larval growth [102-104]. In particular, CAMs are suggested to 


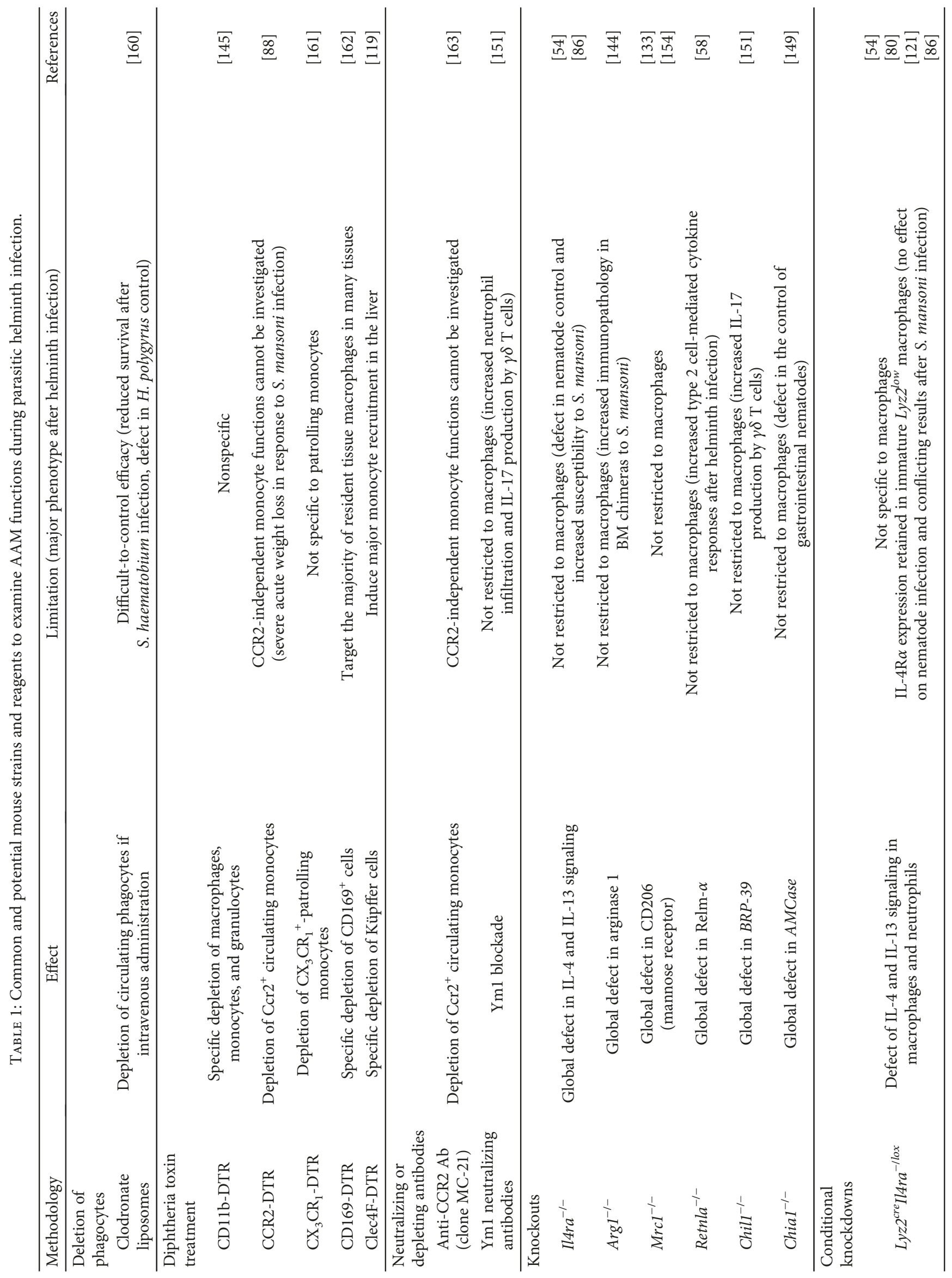




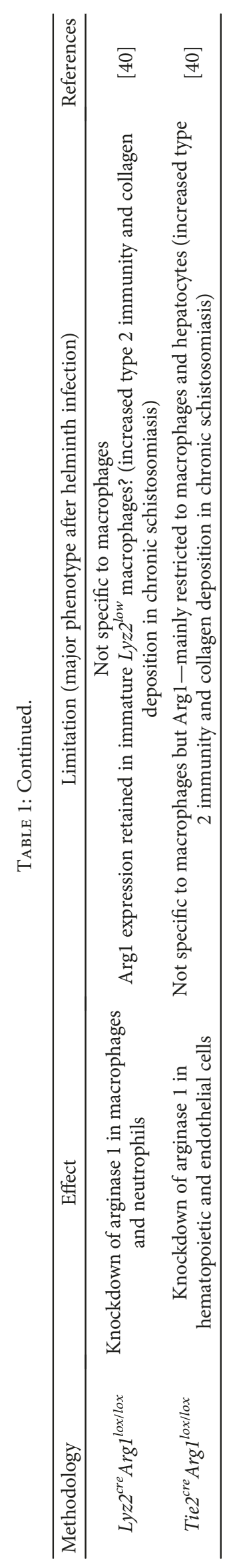


control T. crassiceps infection through NO production. Indeed, blocking of $\mathrm{NO}$ synthase in susceptible wild-type $\mathrm{BALB} / \mathrm{c}$ or resistant $\mathrm{Stat}^{-1-}$ mice resulted in increased parasites loads [105]. Further supporting a role for CAMs in the control of $T$. crassiceps infection, mice lacking migration inhibitory factor (MIF) were highly susceptible despite similar IFN- $\gamma$ levels. Peritoneal macrophages of $M I F^{-1-}$ mice failed to respond to LPS and IFN- $\gamma$ stimuli ex vivo and produce low levels of CAM-associated molecules like IL-12, TNF- $\alpha$, or NO [106]. However, experiments using intraperitoneal or intracranial injection of $M$. corti metacestodes suggested a protective role of type 2 immune responses, with $I 4^{---}$or $\mathrm{Stat}^{-1-}$ mice being highly susceptible and dying after infection $[107,108]$. In addition, a number of studies of various cestode infections suggested that AAMs were mostly associated with immunoregulatory functions to avoid deleterious inflammation to tissues surrounding encysted metacestodes [95, 109-111]. But AAM presence and overexpression of AAM-associated molecules like PD-L1 and PD-L2 were also associated with increased susceptibility to infection with $T$. crassiceps $[112,113]$. Thus, macrophages are present around the developing metacestodes and contribute to the granuloma formation [99], but the role of type 2 immune responses and in particular AAMs in this context remains to be fully elucidated.

3.4. IL-4-Driven Macrophage Proliferation and the Origin of AAMs after Helminth Infection. To understand the contribution of AAMs in helminth infection, understanding their origin is essential. For decades, the established dogma had been that tissue-resident macrophages were derived from circulating monocytes originating from the bone marrow. Challenging this idea, recent reports using fate-mapping experiments brought evidence that resident macrophages are established in the various tissues, including serous cavities, during organogenesis and shortly after birth from yolk sac and fetal liver precursors $[114,115]$. Once established in their tissue niche, resident macrophages are usually characterized by their ability to self-renew by homeostatic proliferation. However, the capacity of resident macrophages to maintain in a long term without contribution of blood monocytes appears to be highly tissue-dependent. Evidence indicates their progressive replacement by bone-marrowderived monocytes in specific tissues like the heart, pancreas, peritoneal and pleural cavities, skin, or intestine, while strain or sex might be important confounding factors [116-118]. Furthermore, monocyte-derived resident macrophages were shown to be able to adopt a phenotypical and transcriptional profile very close to that of embryonic resident macrophages, including the ability to self-renew through proliferation [119]. Similarly, during inflammatory processes, the expansion of macrophage populations is mostly associated with recruitment on monocytes but can also result from local proliferation of resident cells. Indeed, when initially attempting to deplete macrophages to investigate their role during mouse infection with the filarial nematode Litomosoides sigmodontis by clodronate treatment, Jenkins and colleagues found that tissue-resident macrophages were directly responding to IL-4 that induced their proliferation beyond homeostatic levels induced by CSF-1 $[120,121]$. Local macrophage proliferation turned out to be not restricted to the pleura but also apparent in the liver, small intestine lamina propria, and peritoneal cavity after $H$. polygyrus infection whereas treatment with IL-4 complexes was sufficient to induce proliferation [122]. In addition, recent data highlighted the existence of an amplification system in addition to IL-4 that is needed for type 2 immunity within distinct tissues. $N$. brasiliensis migration through the lung induced IL-4R $\alpha$-dependent production of surfactant protein- (SP-) A by alveolar epithelial cells. Macrophages from $S P-A^{-1-}$ mice infected with $N$. brasiliensis or treated with IL-4c failed to proliferate and to upregulate AAM markers [123]. Consistent with a direct role of SP-A on macrophages to boost IL-4mediated macrophages activation, in vitro treatment with SP-A and IL-4 increased proliferation and upregulation of AAM markers in WT but not $\mathrm{IlAra}^{-1-}$ alveolar macrophages, compared to IL-4 treatment alone [123]. Similarly, SP-D was also shown to interact with alveolar macrophages after $N$. brasiliensis infection and to increase expression of AAM markers after IL-4/IL-13 treatment ex vivo [37]. Interestingly, the complement factor C1q, but not SP-A, was shown to have a similar effect on peritoneal macrophages and in the liver while alveolar macrophages were not responsive to $\mathrm{Clq}$ [123]. Thus, IL-4 induces production of SP-A and C1q and the expression of their receptor, myosin 18A, suggesting the existence within different tissues of an amplification system for local type 2 immune responses [123]. In addition to IL-4, IL-33 has also been shown to mediate macrophage proliferation through a distinct mechanism [124].

Local amplification is not the unique source of the AAM response after helminth infection. Indeed, egg-induced inflammation after S. mansoni infection causes the development of AAM-rich liver granulomas. As opposed to that observed with other helminth models, S. mansoni egg deposition is associated with a recruitment of Ly6 $\mathrm{C}^{\text {hi }}$ monocytes of bone-marrow origin and these inflammatory monocytes differentiate into macrophages [87]. Although Küpffer cells (liver-resident macrophages) do respond to the infection and seem to proliferate at low levels, the main response rather seemed to be due to monocyte recruitment and differentiation into AAMs [88]. Although it remains unclear whether signaling through IL- $4 \mathrm{R} \alpha$ is involved in the recruitment and responses of recruited monocytes, AAMs derived from infiltrating monocytes or tissue-resident macrophage proliferation have distinct phenotypes, with monocyte-derived AAMs being associated with immune regulation properties [117, 125]. AAM origin could therefore influence their contribution to pathology as observed after bleomycine-induced lung fibrosis [126] or protection against pathogens [117]. Interestingly, recruited monocytes to the liver after $S$. mansoni infection acquire a phenotype of liver resident macrophages after alternative activation that is dependent on vitamin A [127]. Whether these macrophages of bone-marrow origin in the liver take over the niche of Küpffer cells as observed in diphtheria toxin-treated Clec4f-DTR mice or Küpffer cell necroptosis caused by $L$. monocytogenes infection is unknown [39, 119], like it is also unknown what signal(s) induce(s) monocyte recruitment to the liver where 
S. mansoni eggs are responsible for elevated IL-4 and IL-13 responses.

3.5. Effector Molecules. Following parasitic helminth infection, IL-4/13 signaling in AAMs results in the activation of the transcription factor signal transducer and activator of transcription (STAT) 6 [128]. Upon activation in macrophages, STAT- 6 binds to promotor regions of multiple genes and promotes their expression that results in AAM polarization and proliferation. Of note, STAT- 6 also promotes the expression to other transcription factors such as peroxisome proliferator-activated receptor- (PPAR-) $\gamma$, Krüppel-like factor (KLF) 4, or interferon regulatory factor (IRF) 4. Upon polarization, AAMs upregulate the gene expression of a range of signature proteins including the mannose receptor (CD206), Arg1, chitinases and chitinase-like molecules, resistin-like molecules, or programmed cell death ligand 2 (Figure 1). We describe below the understanding of effector molecules produced by AAMs in the laboratory mouse, but as specified before, some of these molecules either are not reliable markers or do not have orthologues in humans. Nonetheless, investigating their functions in mice is important to understand the full spectrum of how AAMs function in different species, including humans.

Interactions between helminths and C-type lectins such as the mannose receptor (CD206, encoded by Mrc1) or the macrophage galactose-type C-type lectin 2 (MGL2 or CD301b) are understudied $[129,130]$. CD206 is upregulated on macrophages upon treatment with IL-4, IL-13, and IL-10 $[22,131]$ as well as prostaglandins PGE1 and PGE2 [130]. Although CD206 has extensively been used in the characterization of AAMs induced upon parasitic helminth infection $[21,75,86]$, its exact role remains uncertain. Helminths secrete large amounts of highly glycosylated proteins that can bind to CD206-expressing immune cells such as macrophages or dendritic cells. Excretory/secretory products of schistosomules from S. mansoni limit the production of proinflammatory cytokines [132-134]. S. mansoni omega-1, a major secreted egg glycoprotein responsible for the induction of type 2 immune responses $[135,136]$, is mainly internalized by CD206-expressing dendritic cells and therefore impairs protein synthesis through its RNAse activity [137]. In addition to S. mansoni, CD206 has been shown to bind other helminth species like $T$. spiralis muscle larvae [138], $T$. muris excretory/secretory products [139], or F. hepatica tegumental proteins [140]. Nonetheless, the role of AAMspecific CD206 expression remains elusive during helminth infection, although CD206 seems to be a relevant surface marker for monocyte-derived AAMs [127]. The macrophage galactose-type C-type lectin 2 (MGL2 or CD301b) is another C-type lectin upregulated in AAMs in response to IL-4 and IL-1 or helminth trigger [129]. While CD $301 b^{+}$dendritic cells have been shown to be essential for the induction of optimal type 2 immune response during OVA immunization or helminth infection [141, 142], CD301b-expressing macrophages appeared to play an important role in wound healing [143].

Arg1 is one of the two isoforms of arginase enzymes that is mainly associated with AAMs. Arg1 is constitutively expressed in the liver, but AAM-specific Arg1 has been shown to control excessive fibrosis via modulation of $\mathrm{CD}^{+} \mathrm{T}$ cell proliferation after chronic parasitic helminth infection has been highlighted using $\operatorname{Lyz} 2^{\text {cre }} \operatorname{Arg} 1^{\text {lox/lox }}$ or Tie $2^{\text {cre }} A r g 1^{\text {lox } / \text { lox }}$ mice [40], as described above. In addition, bone-marrow chimeras using $A r g 1^{-/-}$hematopoietic cells revealed the important role of bone-marrow-derived Arg1 in controlling intestinal inflammation caused by $S$. mansoni eggs by suppressing IL-12/IL-23p40 production and maintaining the Treg/Th17 balance within the intestinal mucosa [144]. Nonetheless, the role of Arg1 might depend on the helminth species as macrophage-specific expression of Arg1 was dispensable for T. muris expulsion whereas it has been involved in promoting the expulsion of $H$. polygyrus and $N$. brasiliensis $[48,53]$. The role of Arg1 further seems to depend on the tissue, as attested by the observation that although lung macrophages are essential to maintain IL-13dependent inflammation and fibrosis [145], macrophagespecific Arg1 is largely dispensable to control helminthdriven lung inflammation [146].

Chitinases are molecules that cleave chitin, a widespread biopolymer of $\mathrm{N}$-acetyl-beta-D-glucosamine that provides structural rigidity to fungi, arthropods, and helminths. In addition to the acidic mammalian chitinase (AMCase), upregulation of chitinase-like molecule expression such as Ym1 (encoded by Chil3), Ym2 (encoded by Chil4), or BRP-39 (encoded by Chill) has been associated with AAMs $[64,122,147,148]$. As opposed to chitinases, chitinase-like molecules do not have chitinase activity. A number of studies have focused on the role of AMCase in allergic lung disease, as its expression is increased in epithelial cells and macrophages in IL-4-dominated inflammation in the lung and intestinal tract. However, it recently turned out that AMCase is largely dispensable for allergic responses in the lung while essential for priming protective effector responses against parasitic nematodes $H$. polygyrus and $N$. brasiliensis [149]. Whether AAMs could be a source of AMCase after helminth infection remains to be determined. Ym1 and Ym2 do not have human orthologs, which explains why the role of these proteins has been disregarded even though $\mathrm{Ym} 1$ is strongly upregulated in AAMs and has been shown to attract eosinophils [150]. Mouse BRP-39 however is an ortholog of the human YKL-40 (encoded by CHI3L1), and an elegant study using neutralizing anti-Ym1 antibody treatment or Chill ${ }^{-1-}$ mice suggested a role of $\mathrm{Ym} 1$ and chitinase-like molecules in inducing IL-17 secretion by $\gamma \delta$-T cells to promote neutrophil recruitment in the lung after infection with $N$. brasiliensis [151]. Although nematode-induced Ym1 results in IL-17 responses and lung injury, AAMs can control IL-17-driven inflammation in the lung [59]. Moreover, lung neutrophil infiltration after $N$. brasiliensis infection crosstalk and regulate lung AAMs for rapid worm killing [60].

Resistin-like molecule- $\alpha$ (Relm- $\alpha$, encoded by Retnla), otherwise known as "found in inflammatory zone 1" (Fizz1), is a member of a family of cysteine-rich secreted proteins that make important contributions to host control of helminth infections [152]. Relm- $\alpha$ is upregulated in AAMs and also in eosinophils and epithelial cells and is predominantly 
found in the lungs upon type 2 inflammation, such as allergic inflammation or exposure to parasitic helminths [153]. Retnla $^{-1-}$ mice displayed increased type 2 cell-mediated cytokine responses with elevated IL-4, IL-13, and IL-5 production by $\mathrm{CD} 4^{+} \mathrm{T}$ cells $[58,154]$. Relm- $\alpha$ was shown to directly bind to $\mathrm{CD}^{+} \mathrm{T}$ cells and inhibit type 2 cytokine production, with no effect on $\mathrm{T}$ cell activation or proliferation [154]. During S. mansoni egg-induced inflammation, Relm- $\alpha$ is also expressed by epithelial cells and eosinophils, but coculture experiments showed that Relm- $\alpha$-dependent inhibition of type 2 cytokine production can be supported by macrophages [154]. However, in the liver of S. mansoni-infected mice, eosinophils appear to be the main, if not the exclusive, source of Relm- $\alpha$ [58]. In addition, Relm- $\alpha$ seems to be dominating over intestinal Relm- $\beta$ in the control of $N$. brasiliensis [155]. There exists a strict dependency of Relm- $\alpha$ expression on type 2 cytokines as mice deficient for IL-4R $\alpha$, IL-4, IL-13, or STAT-6 do not have elevated levels of Relm- $\alpha$ following an immune challenge [156]. Thus, Relm- $\alpha$ appears to serve as a negative feedback loop regulating the magnitude of host response to helminth infection. Besides, Relm- $\alpha$ appeared to be a mediator of tissue repair as the absence of AAM-derived Relm- $\alpha$ in skin wounds of $L y z 2^{\text {cre }} \mathrm{IlAra}^{-l l o x}$ mice was associated with a failure of the healing response [157].

Programme death ligand 2 (PD-L2) is upregulated in monocyte-derived AAMs, whereas it is poorly expressed on IL-4-treated resident macrophages [158]. PD-L2 is a ligand of PD-1, a potent inhibitory receptor expressed on effector $\mathrm{T}$ cells, and macrophage PD-L2 has been shown to potently inhibit $\mathrm{T}$ cell proliferation [159]. PD-L2 expression is upregulated in lung macrophages after $N$. brasiliensis infection whereas STAT-6-deficient mice display low levels of macrophage PD-L2 [159]. In addition, in vivo blockade of PD-L2 during $N$. brasiliensis infection increases type 2 cell-mediated cytokine responses in the lung, further indicating that AAMs inhibit Th2 cells by expression of PDL2. In addition to its effector function, PD-L2 is used as a relevant surface marker to distinguish between resident and monocyte-derived macrophages following antigenic stimulation or S. mansoni infection $[125,127]$. Differences in the dynamics of macrophage responses between mouse strains could explain variation in susceptibility to helminth infections. Campbell and colleagues showed that macrophage responses against $L$. sigmodontis infection in susceptible $\mathrm{BALB} / \mathrm{c}$ mice was dominated by infiltration of monocytes with the immunosuppressive PD-L2 ${ }^{+}$phenotype, as opposed to resistant C57BL/6 mice in which expansion of resident cells was the main source of macrophages [117].

\section{Conclusion and Future Directions}

Parasitic helminths share many aspects as they all induce strong type 2 cell-mediated immune responses. However, they are not completely equal in terms of the immune responses they induce and the ability of the mounted immunity to deal with effective clearance of the parasite, avoid immunopathology, and/or promote tolerance of chronic low-burden infection. Powerful tools have been used to study macrophage origin, polarization, activation, and function after helminth infection, and yet, many questions are still unresolved. What makes the difference between filarial nematodes inducing local macrophage proliferation via IL-4 and S. mansoni eggs promoting monocyte recruitment? What functions are mediated by AAMs during acute schistosomiasis where conflicting results arise from the use of Lyz2 ${ }^{\text {cre }} I l 4 \mathrm{ra}^{-l l o x}$ mice? Would new gene identification from single-cell sequencing on macrophage populations in the various tissues affected by helminth infection such as the skin, lung, liver, or intestine and depending on given time points following infection ultimately permit the development of novel conditional knockdown mouse models to provide clearer information on the role of such plural macrophage responses? What are the interactions between liver resident macrophages, granuloma-derived macrophages after S. mansoni infection, and hepatic stellate cells in the regulation of fibrosis? Although there is no doubt that our understanding is still limited on how the host immune system and macrophage responses have been shaped during evolution to deal with parasitic helminths and whether we can truly consider them as "old friends," we are convinced that new insights will be acquired in the near future to resolve these questions and others.

\section{Conflicts of Interest}

The authors declare that they have no conflicts of interest.

\section{Acknowledgments}

Marion Rolot and Benjamin G. Dewals are supported by grants from Fonds de la Recherche Scientifique - FNRS in Belgium as research fellow of the FRIA and research associate of the FNRS, respectively.

\section{References}

[1] N. L. Harris and P. Loke, "Recent advances in type-2-cellmediated immunity: insights from helminth infection," Immunity, vol. 47, no. 6, pp. 1024-1036, 2017.

[2] R. L. Pullan, J. L. Smith, R. Jasrasaria, and S. J. Brooker, "Global numbers of infection and disease burden of soil transmitted helminth infections in 2010," Parasites \& Vectors, vol. 7, no. 1, p. 37, 2014.

[3] F. Kenyon, F. Hutchings, C. Morgan-Davies, J. van Dijk, and D. J. Bartley, "Worm control in livestock: bringing science to the field," Trends in Parasitology, vol. 33, no. 9, pp. 669-677, 2017.

[4] J. Bethony, S. Brooker, M. Albonico et al., "Soil-transmitted helminth infections: ascariasis, trichuriasis, and hookworm," The Lancet, vol. 367, no. 9521, pp. 1521-1532, 2006.

[5] M. J. Taylor, A. Hoerauf, and M. Bockarie, "Lymphatic filariasis and onchocerciasis," The Lancet, vol. 376, no. 9747, pp. 1175-1185, 2010.

[6] F. Mutapi, R. Maizels, A. Fenwick, and M. Woolhouse, "Human schistosomiasis in the post mass drug administration era," The Lancet Infectious Diseases, vol. 17, no. 2, pp. e42-e48, 2017. 
[7] R. M. Maizels and M. Yazdanbakhsh, "Immune regulation by helminth parasites: cellular and molecular mechanisms," Nature Reviews Immunology, vol. 3, no. 9, pp. 733-744, 2003.

[8] J. Sotillo, R. Toledo, J. Mulvenna, and A. Loukas, "Exploiting helminth-host interactomes through big data," Trends in Parasitology, vol. 33, no. 11, pp. 875-888, 2017.

[9] C. J. C. Johnston, D. J. Smyth, R. B. Kodali et al., "A structurally distinct TGF- $\beta$ mimic from an intestinal helminth parasite potently induces regulatory T cells," Nature Communications, vol. 8, no. 1, p. 1741, 2017.

[10] R. M. Maizels and K. A. Smith, "Regulatory T cells in infection," Advances in Immunology, vol. 112, pp. 73-136, 2011.

[11] R. M. Maizels and H. J. McSorley, "Regulation of the host immune system by helminth parasites," The Journal of Allergy and Clinical Immunology, vol. 138, no. 3, pp. 666675, 2016.

[12] W. G. C. Horsnell and F. Brombacher, "Genes associated with alternatively activated macrophages discretely regulate helminth infection and pathogenesis in experimental mouse models," Immunobiology, vol. 215, no. 9-10, pp. 704-708, 2010.

[13] P. J. Hotez, D. A. P. Bundy, K. Beegle et al., "Helminth infections: soil-transmitted helminth infections and schistosomiasis," in Disease Control Priorities in Developing Countries, D. T. Jamison, J. G. Breman, A. R. Measham, G. Alleyne, M. Claeson, D. B. Evans, P. Jha, A. Mills, and P. Musgrove, Eds., Oxford University Press, Washington, DC, 2006.

[14] R. Medzhitov, D. S. Schneider, and M. P. Soares, "Disease tolerance as a defense strategy," Science, vol. 335, no. 6071, pp. 936-941, 2012.

[15] S. J. Davies, J. L. Grogan, R. B. Blank, K. C. Lim, R. M. Locksley, and J. McKerrow, "Modulation of blood fluke development in the liver by hepatic $\mathrm{CD} 4^{+}$lymphocytes," Science, vol. 294, no. 5545, pp. 1358-1361, 2001.

[16] M. Osbourn, D. C. Soares, F. Vacca et al., "HpARI protein secreted by a helminth parasite suppresses interleukin-33," Immunity, vol. 47, no. 4, article e735, pp. 739-751.e5, 2017.

[17] D. Ramanan, R. Bowcutt, S. C. Lee et al., "Helminth infection promotes colonization resistance via type 2 immunity," Science, vol. 352, no. 6285, pp. 608-612, 2016.

[18] M. M. Harnett and W. Harnett, "Can parasitic worms cure the modern world's ills?," Trends in Parasitology, vol. 33, no. 9, pp. 694-705, 2017.

[19] L. J. Wammes, H. Mpairwe, A. M. Elliott, and M. Yazdanbakhsh, "Helminth therapy or elimination: epidemiological, immunological, and clinical considerations," The Lancet Infectious Diseases, vol. 14, no. 11, pp. 1150-1162, 2014.

[20] E. Metchnikoff, L'immunité dans les maladies infectieuses, Masson et Cie, Librairie de l'académie de médecine, Paris, France, 1901.

[21] S. J. Van Dyken and R. M. Locksley, "Interleukin-4- and interleukin-13-mediated alternatively activated macrophages: roles in homeostasis and disease," Annual Review of Immunology, vol. 31, no. 1, pp. 317-343, 2013.

[22] M. Stein, S. Keshav, N. Harris, and S. Gordon, "Interleukin 4 potently enhances murine macrophage mannose receptor activity: a marker of alternative immunologic macrophage activation," The Journal of Experimental Medicine, vol. 176, no. 1, pp. 287-292, 1992.
[23] M. Beyer, M. R. Mallmann, J. Xue et al., "High-resolution transcriptome of human macrophages," PLoS One, vol. 7, no. 9, article e45466, 2012.

[24] M. Jaguin, N. Houlbert, O. Fardel, and V. Lecureur, "Polarization profiles of human M-CSF-generated macrophages and comparison of M1-markers in classically activated macrophages from GM-CSF and M-CSF origin," Cellular Immunology, vol. 281, no. 1, pp. 51-61, 2013.

[25] A. A. Tarique, J. Logan, E. Thomas, P. G. Holt, P. D. Sly, and E. Fantino, "Phenotypic, functional, and plasticity features of classical and alternatively activated human macrophages," American Journal of Respiratory Cell and Molecular Biology, vol. 53, no. 5, pp. 676-688, 2015.

[26] J. Xue, S. V. Schmidt, J. Sander et al., “Transcriptome-based network analysis reveals a spectrum model of human macrophage activation," Immunity, vol. 40, no. 2, pp. 274-288, 2014.

[27] P. J. Murray, J. E. Allen, S. K. Biswas et al., "Macrophage activation and polarization: nomenclature and experimental guidelines," Immunity, vol. 41, no. 1, pp. 14-20, 2014.

[28] F. Ginhoux, J. L. Schultze, P. J. Murray, J. Ochando, and S. K. Biswas, "New insights into the multidimensional concept of macrophage ontogeny, activation and function," Nature Immunology, vol. 17, no. 1, pp. 34-40, 2016.

[29] P. J. Murray, "Macrophage polarization," Annual Review of Physiology, vol. 79, no. 1, pp. 541-566, 2017.

[30] S. Gordon and F. O. Martinez, "Alternative activation of macrophages: mechanism and functions," Immunity, vol. 32, no. 5, pp. 593-604, 2010.

[31] J. Pesce, M. Kaviratne, T. R. Ramalingam et al., "The IL-21 receptor augments Th2 effector function and alternative macrophage activation," The Journal of Clinical Investigation, vol. 116, no. 7, pp. 2044-2055, 2006.

[32] N. E. Humphreys, D. Xu, M. R. Hepworth, F. Y. Liew, and R. K. Grencis, "IL-33, a potent inducer of adaptive immunity to intestinal nematodes," Journal of Immunology, vol. 180, no. 4, pp. 2443-2449, 2008.

[33] M. Kurowska-Stolarska, B. Stolarski, P. Kewin et al., "IL-33 amplifies the polarization of alternatively activated macrophages that contribute to airway inflammation," Journal of Immunology, vol. 183, no. 10, pp. 6469-6477, 2009.

[34] J. Esser-von Bieren, I. Mosconi, R. Guiet et al., “Antibodies trap tissue migrating helminth larvae and prevent tissue damage by driving IL- $4 \mathrm{R} \alpha$-independent alternative differentiation of macrophages," PLoS pathogens, vol. 9, no. 11, article e1003771, 2013.

[35] J. Esser-von Bieren, B. Volpe, M. Kulagin et al., “Antibodymediated trapping of helminth larvae requires $\mathrm{CD} 11 \mathrm{~b}$ and Fc $\gamma$ receptor I," The Journal of Immunology, vol. 194, no. 3, pp. 1154-1163, 2015.

[36] J. Esser-von Bieren, B. Volpe, D. B. Sutherland et al., "Immune antibodies and helminth products drive CXCR2dependent macrophage-myofibroblast crosstalk to promote intestinal repair," PLoS pathogens, vol. 11, no. 3, article e1004778, 2015.

[37] S. Thawer, J. Auret, C. Schnoeller et al., "Surfactant protein-D is essential for immunity to helminth infection," PLoS Pathogens, vol. 12, no. 2, article e1005461, 2016.

[38] L. Bosurgi, Y. G. Cao, M. Cabeza-Cabrerizo et al., "Macrophage function in tissue repair and remodeling requires IL-4 or IL-13 with apoptotic cells," Science, vol. 356, no. 6342, pp. 1072-1076, 2017. 
[39] C. Bleriot, T. Dupuis, G. Jouvion, G. Eberl, O. Disson, and M. Lecuit, "Liver-resident macrophage necroptosis orchestrates type 1 microbicidal inflammation and type-2mediated tissue repair during bacterial infection," Immunity, vol. 42, no. 1, pp. 145-158, 2015.

[40] J. T. Pesce, T. R. Ramalingam, M. M. Mentink-Kane et al., "Arginase-1-expressing macrophages suppress Th2 cytokine-driven inflammation and fibrosis," PLoS Pathogens, vol. 5, no. 4, article e1000371, 2009.

[41] J. P. Carson, G. A. Ramm, M. W. Robinson, D. P. McManus, and G. N. Gobert, "Schistosome-induced fibrotic disease: the role of hepatic stellate cells," Trends in Parasitology, vol. 34, no. 6, pp. 524-540, 2018.

[42] T. Mchedlidze, M. Waldner, S. Zopf et al., "Interleukin-33dependent innate lymphoid cells mediate hepatic fibrosis," Immunity, vol. 39, no. 2, pp. 357-371, 2013.

[43] C. M. Minutti, J. A. Knipper, J. E. Allen, and D. M. W. Zaiss, "Tissue-specific contribution of macrophages to wound healing," Seminars in Cell \& Developmental Biology, vol. 61, pp. 3-11, 2017.

[44] T. A. Wynn and K. M. Vannella, "Macrophages in tissue repair, regeneration, and fibrosis," Immunity, vol. 44, no. 3, pp. 450-462, 2016.

[45] J. Behnke and P. D. Harris, "Heligmosomoides bakeri: a new name for an old worm?," Trends in Parasitology, vol. 26, no. 11, pp. 524-529, 2010.

[46] L. A. Reynolds, K. J. Filbey, and R. M. Maizels, "Immunity to the model intestinal helminth parasite Heligmosomoides polygyrus," Seminars in Immunopathology, vol. 34, no. 6, pp. 829-846, 2012.

[47] R. M. Anthony, L. I. Rutitzky, J. F. Urban, M. J. Stadecker, and W. C. Gause, "Protective immune mechanisms in helminth infection," Nature Reviews Immunology, vol. 7, no. 12, pp. 975-987, 2007.

[48] R. M. Anthony, J. F. Urban, F. Alem et al., "Memory $\mathrm{T}_{\mathrm{H}} 2$ cells induce alternatively activated macrophages to mediate protection against nematode parasites," Nature Medicine, vol. 12, no. 8, pp. 955-960, 2006.

[49] M. Weng, D. Huntley, I. F. Huang et al., "Alternatively activated macrophages in intestinal helminth infection: effects on concurrent bacterial colitis," Journal of Immunology, vol. 179, no. 7, pp. 4721-4731, 2007.

[50] T. A. Reese, B. S. Wakeman, H. S. Choi et al., "Helminth infection reactivates latent $\gamma$-herpesvirus via cytokine competition at a viral promoter," Science, vol. 345, no. 6196, pp. 573-577, 2014.

[51] M. Camberis, G. Le Gros, and J. Urban Jr, "UNIT 19.12 Animal model of Nippostrongylus brasiliensis and Heligmosomoides polygyrus," Current Protocols in Immunology, pp. 19.12.1-19.12.27, 2003, Chapter 19.

[52] M. C. Siracusa, J. J. Reece, J. F. Urban Jr., and A. L. Scott, "Dynamics of lung macrophage activation in response to helminth infection," Journal of Leukocyte Biology, vol. 84, no. 6, pp. 1422-1433, 2008.

[53] A. Zhao, J. F. Urban Jr, R. M. Anthony et al., "Th2 cytokineinduced alterations in intestinal smooth muscle function depend on alternatively activated macrophages," Gastroenterology, vol. 135, no. 1, pp. 217-225.e1, 2008.

[54] D.'. B. R. Herbert, C. Hölscher, M. Mohrs et al., “Alternative macrophage activation is essential for survival during schistosomiasis and downmodulates $\mathrm{T}$ helper 1 responses and immunopathology," Immunity, vol. 20, no. 5, pp. 623-635, 2004.

[55] B. . J. Marsland, M. Kurrer, R. Reissmann, N. . L. Harris, and M. Kopf, "Nippostrongylus brasiliensis infection leads to the development of emphysema associated with the induction of alternatively activated macrophages," European Journal of Immunology, vol. 38, no. 2, pp. 479-488, 2008.

[56] H. Mearns, W. G. C. Horsnell, J. C. Hoving et al., "Interleukin-4-promoted T helper 2 responses enhance Nippostrongylus brasiliensis-induced pulmonary pathology," Infection and Immunity, vol. 76, no. 12, pp. 5535-5542, 2008.

[57] J. J. Reece, M. C. Siracusa, T. L. Southard, C. F. Brayton, J. F. Urban, and A. L. Scott, "Hookworm-induced persistent changes to the immunological environment of the lung," Infection and Immunity, vol. 76, no. 8, pp. 3511-3524, 2008.

[58] J. T. Pesce, T. R. Ramalingam, M. S. Wilson et al., "Retnla (relm $\alpha$ /fizz1) suppresses helminth-induced Th2-type immunity,” PLoS Pathogens, vol. 5, no. 4, article e1000393, 2009.

[59] F. Chen, Z. Liu, W. Wu et al., "An essential role for $\mathrm{T}_{\mathrm{H}}$ 2-type responses in limiting acute tissue damage during experimental helminth infection," Nature Medicine, vol. 18, no. 2, pp. 260-266, 2012.

[60] F. Chen, W. Wu, A. Millman et al., "Neutrophils prime a long-lived effector macrophage phenotype that mediates accelerated helminth expulsion," Nature Immunology, vol. 15, no. 10, pp. 938-946, 2014.

[61] P. Loke, I. Gallagher, M. G. Nair et al., “Alternative activation is an innate response to injury that requires $\mathrm{CD} 4^{+} \mathrm{T}$ cells to be sustained during chronic infection," Journal of Immunology, vol. 179, no. 6, pp. 3926-3936, 2007.

[62] P.'n. Loke, A. S. MacDonald, A. Robb, R. M. Maizels, and J. E. Allen, "Alternatively activated macrophages induced by nematode infection inhibit proliferation via cell-to-cell contact," European Journal of Immunology, vol. 30, no. 9, pp. 2669-2678, 2000.

[63] K. J. Mylonas, M. G. Nair, L. Prieto-Lafuente, D. Paape, and J. E. Allen, "Alternatively activated macrophages elicited by helminth infection can be reprogrammed to enable microbial killing," Journal of Immunology, vol. 182, no. 5, pp. 30843094, 2009.

[64] G. D. Thomas, D. Ruckerl, B. H. Maskrey, P. D. Whitfield, M. L. Blaxter, and J. E. Allen, "The biology of nematodeand IL4R $\alpha$-dependent murine macrophage polarization in vivo as defined by RNA-Seq and targeted lipidomics," Blood, vol. 120, no. 25, pp. e93-e104, 2012.

[65] J. D. Turner, N. Pionnier, J. Furlong-Silva et al., "Interleukin4 activated macrophages mediate immunity to filarial helminth infection by sustaining CCR3-dependent eosinophilia," PLoS Pathogens, vol. 14, no. 3, article e1006949, 2018.

[66] D. Ruckerl, S. J. Jenkins, N. N. Laqtom et al., "Induction of IL$4 \mathrm{R} \alpha$-dependent microRNAs identifies PI3K/Akt signaling as essential for IL-4-driven murine macrophage proliferation in vivo," Blood, vol. 120, no. 11, pp. 2307-2316, 2012.

[67] S. Donnelly, S. M. O'Neill, M. Sekiya, G. Mulcahy, and J. P. Dalton, "Thioredoxin peroxidase secreted by Fasciola hepatica induces the alternative activation of macrophages," Infection and Immunity, vol. 73, no. 1, pp. 166-173, 2004.

[68] R. J. Flynn, J. A. Irwin, M. Olivier, M. Sekiya, J. P. Dalton, and G. Mulcahy, “Alternative activation of ruminant macrophages 
by Fasciola hepatica," Veterinary Immunology and Immunopathology, vol. 120, no. 1-2, pp. 31-40, 2007.

[69] C. C. Stempin, C. C. Motran, M. P. Aoki, C. R. Falcon, F. M. Cerban, and L. Cervi, "PD-L2 negatively regulates Th1mediated immunopathology during Fasciola hepatica infection," Oncotarget, vol. 7, no. 47, pp. 77721-77731, 2016.

[70] D. G. Colley, A. L. Bustinduy, W. E. Secor, and C. H. King, "Human schistosomiasis," The Lancet, vol. 383, no. 9936, pp. 2253-2264, 2014.

[71] A. W. Cheever, K. F. Hoffmann, and T. A. Wynn, "Immunopathology of Schistosomiasis mansoni in mice and men," Immunology Today, vol. 21, no. 9, pp. 465-466, 2000.

[72] P. G. Fallon, "Immunopathology of schistosomiasis: a cautionary tale of mice and men," Immunology Today, vol. 21, no. 1, pp. 29-35, 2000.

[73] J. M. Grzych, E. Pearce, A. Cheever et al., "Egg deposition is the major stimulus for the production of Th2 cytokines in murine schistosomiasis mansoni," The Journal of Immunology, vol. 146, no. 4, pp. 1322-1327, 1991.

[74] E. J. Pearce, P. Caspar, J. M. Grzych, F. A. Lewis, and A. Sher, "Downregulation of Th1 cytokine production accompanies induction of Th2 responses by a parasitic helminth, Schistosoma mansoni," The Journal of Experimental Medicine, vol. 173, no. 1, pp. 159-166, 1991.

[75] E. J. Pearce and A. S. MacDonald, "The immunobiology of schistosomiasis," Nature Reviews Immunology, vol. 2, no. 7, pp. 499-511, 2002.

[76] A. T. Vella and E. J. Pearce, "CD4+ Th2 response induced by Schistosoma mansoni eggs develops rapidly, through an early, transient, Th0-like stage," Journal of Immunology, vol. 148, pp. 2283-2290, 1992.

[77] E. Hams, G. Aviello, and P. G. Fallon, “The schistosoma granuloma: friend or foe?," Frontiers in Immunology, vol. 4, p. 89, 2013.

[78] L. Barron and T. A. Wynn, "Macrophage activation governs schistosomiasis-induced inflammation and fibrosis," European Journal of Immunology, vol. 41, no. 9, pp. 2509-2514, 2011.

[79] D. R. Herbert, T. Orekov, C. Perkins, M. E. Rothenberg, and F. D. Finkelman, "IL- $4 \mathrm{R} \alpha$ expression by bone marrowderived cells is necessary and sufficient for host protection against acute schistosomiasis," The Journal of Immunology, vol. 180, no. 7, pp. 4948-4955, 2008.

[80] K. M. Vannella, L. Barron, L. A. Borthwick et al., "Incomplete deletion of IL-4R $\alpha$ by LysM ${ }^{\text {Cre }}$ reveals distinct subsets of M2 macrophages controlling inflammation and fibrosis in chronic schistosomiasis," PLoS Pathogens, vol. 10, no. 9, article e1004372, 2014.

[81] L. R. Brunet, F. D. Finkelman, A. W. Cheever, M. A. Kopf, and E. J. Pearce, "IL-4 protects against TNF-alpha-mediated cachexia and death during acute schistosomiasis," The Journal of Immunology, vol. 159, no. 2, pp. 777-785, 1997.

[82] P. G. Fallon, E. J. Richardson, G. J. McKenzie, and A. N. J. McKenzie, "Schistosome infection of transgenic mice defines distinct and contrasting pathogenic roles for IL-4 and IL-13: IL-13 is a profibrotic agent," The Journal of Immunology, vol. 164, no. 5, pp. 2585-2591, 2000.

[83] K. F. Hoffmann, A. W. Cheever, and T. A. Wynn, "IL-10 and the dangers of immune polarization: excessive type 1 and type 2 cytokine responses induce distinct forms of lethal immunopathology in murine schistosomiasis," The
Journal of Immunology, vol. 164, no. 12, pp. 6406-6416, 2000.

[84] D. Jankovic, M. C. Kullberg, N. Noben-Trauth et al., "Schistosome-infected IL-4 receptor knockout (KO) mice, in contrast to IL-4 KO mice, fail to develop granulomatous pathology while maintaining the same lymphokine expression profile," Journal of Immunology, vol. 163, pp. 337-342, 1999.

[85] A. C. La Flamme, E. A. Patton, B. Bauman, and E. J. Pearce, "IL-4 plays a crucial role in regulating oxidative damage in the liver during schistosomiasis," Journal of Immunology, vol. 166, no. 3, pp. 1903-1911, 2001.

[86] B. G. Dewals, R. G. Marillier, J. C. Hoving, M. Leeto, A. Schwegmann, and F. Brombacher, "IL- $4 \mathrm{R} \alpha$-independent expression of mannose receptor and $\mathrm{Ym} 1$ by macrophages depends on their IL-10 responsiveness," PLoS Neglected Tropical Diseases, vol. 4, no. 5, article e689, 2010.

[87] N. M. Girgis, U. M. Gundra, L. N. Ward, M. Cabrera, U. Frevert, and P.'. Loke, "Ly6C $\mathrm{C}^{\text {high }}$ monocytes become alternatively activated macrophages in schistosome granulomas with help from CD4+ cells," PLoS Pathogens, vol. 10, no. 6, article e1004080, 2014.

[88] M. Nascimento, S. C. Huang, A. Smith et al., "Ly6C" monocyte recruitment is responsible for Th2 associated hostprotective macrophage accumulation in liver inflammation due to schistosomiasis," PLoS Pathogens, vol. 10, no. 8, article e1004282, 2014.

[89] T. R. Ramalingam, J. T. Pesce, F. Sheikh et al., "Unique functions of the type II interleukin 4 receptor identified in mice lacking the interleukin 13 receptor $\alpha 1$ chain," Nature Immunology, vol. 9, no. 1, pp. 25-33, 2008.

[90] M. G. Chiaramonte, D. D. Donaldson, A. W. Cheever, and T. A. Wynn, "An IL-13 inhibitor blocks the development of hepatic fibrosis during a T-helper type 2-dominated inflammatory response," Journal of Clinical Investigation, vol. 104, no. 6, pp. 777-785, 1999.

[91] P. Boireau and Food and Agriculture Organization of the United Nations., and World Health Organization, Multicriteria-Based Ranking for Risk Management of Food-Borne Parasites : Report of a Joint FAO/WHO Expert Meeting, 37 September 2012, FAO Headquarters, Rome, Italy, Food and Agriculture Organization of the United Nations; World Health Organization, Rome, Italy Geneva, Switzerland, 2014.

[92] A. Oksanen, M. Siles-Lucas, J. Karamon et al., "The geographical distribution and prevalence of Echinococcus multilocularis in animals in the European Union and adjacent countries: a systematic review and meta-analysis," Parasites \& Vectors, vol. 9, no. 1, p. 519, 2016.

[93] J. I. Alvarez, B. B. Mishra, U. M. Gundra, P. K. Mishra, and J. M. Teale, "Mesocestoides corti intracranial infection as a murine model for neurocysticercosis," Parasitology, vol. 137, no. 3, pp. 359-372, 2010.

[94] A. E. Cardona, B. I. Restrepo, J. M. Jaramillo, and J. M. Teale, "Development of an animal model for neurocysticercosis: immune response in the central nervous system is characterized by a predominance of $\gamma \delta$ T cells," The Journal of Immunology, vol. 162, no. 2, pp. 995-1002, 1999.

[95] L. Terrazas, "The complex role of pro- and anti-inflammatory cytokines in cysticercosis: immunological lessons from experimental and natural hosts," Current Topics in Medicinal Chemistry, vol. 8, no. 5, pp. 383-392, 2008.

[96] S. Wang, T. Yang, X. Zhang et al., "Construction of in vivo fluorescent imaging of Echinococcus granulosus in a mouse 
model," The Korean Journal of Parasitology, vol. 54, no. 3, pp. 291-299, 2016.

[97] A. Ito, R. D. Honey, T. Scanton, M. W. Lightowlersr, and M. D. Rickard, "Analysis of antibody responses to Hymenolepis nana infection in mice by the enzyme-linked immunosorbent assay and immunoprecipitation," Parasite Immunology, vol. 10, no. 3, pp. 265-277, 1988.

[98] D. M. McKay, D. W. Halton, M. D. McCaigue, C. F. Johnston, I. Fairweather, and C. Shaw, "Hymenolepis diminuta: intestinal goblet cell response to infection in male C57 mice," Experimental Parasitology, vol. 71, no. 1, pp. 9-20, 1990.

[99] A. Diaz, C. Sagasti, and C. Casaravilla, "Granulomatous responses in larval taeniid infections," Parasite Immunology, vol. 40, no. 5, article e12523, 2018.

[100] S. A. Toenjes and R. E. Kuhn, “The initial immune response during experimental cysticercosis is of the mixed Th1/Th2 type," Parasitology Research, vol. 89, no. 5, pp. 407-413, 2003.

[101] S. A. Toenjes, R. J. Spolski, K. A. Mooney, and R. E. Kuhn, "The systemic immune response of BALB/c mice infected with larval Taenia crassiceps is a mixed Th1/Th2-type response," Parasitology, vol. 118, no. 6, pp. 623-633, 1999.

[102] M. Rodríguez-Sosa, R. Saavedra, E. P. Tenorio, L. E. Rosas, A. R. Satoskar, and L. I. Terrazas, "A STAT4-dependent Th1 response is required for resistance to the helminth parasite Taenia crassiceps," Infection and Immunity, vol. 72, no. 8, pp. 4552-4560, 2004.

[103] L. I. Terrazas, R. Bojalil, T. Govezensky, and C. Larralde, "Shift from an early protective Th1-type immune response to a late permissive Th2-type response in murine cysticercosis (Taenia crassiceps)," The Journal of Parasitology, vol. 84, no. 1, pp. 74-81, 1998.

[104] L. I. Terrazas, M. Cruz, M. Rodríguez-Sosa, R. Bojalil, F. García-Tamayo, and C. Larralde, "Th1-type cytokines improve resistance to murine cysticercosis caused by Taenia crassiceps," Parasitology Research, vol. 85, no. 2, pp. 135141, 1999.

[105] J. Alonso-Trujillo, I. Rivera-Montoya, M. Rodríguez-Sosa, and L. I. Terrazas, "Nitric oxide contributes to host resistance against experimental Taenia crassiceps cysticercosis," Parasitology Research, vol. 100, no. 6, pp. 1341-1350, 2007.

[106] M. Rodríguez-Sosa, L. E. Rosas, J. R. David, R. Bojalil, A. R. Satoskar, and L. I. Terrazas, "Macrophage migration inhibitory factor plays a critical role in mediating protection against the helminth parasite Taenia crassiceps," Infection and Immunity, vol. 71, no. 3, pp. 1247-1254, 2003.

[107] B. B. Mishra, U. M. Gundra, and J. M. Teale, "STAT6 ${ }^{-/-}$mice exhibit decreased cells with alternatively activated macrophage phenotypes and enhanced disease severity in murine neurocysticercosis," Journal of Neuroimmunology, vol. 232, no. 1-2, pp. 26-34, 2011.

[108] A. E. O'Connell, L. A. Kerepesi, G. L. Vandergrift et al., "IL-4 $4^{-1-}$ mice with lethal Mesocestoides corti infectionsreduced Th2 cytokines and alternatively activated macrophages,"ParasiteImmunology,vol.31,no.12,pp.741-749,2009.

[109] J. L. Reyes and L. I. Terrazas, "The divergent roles of alternatively activated macrophages in helminthic infections," Parasite Immunology, vol. 29, no. 12, pp. 609-619, 2007.

[110] C. Terrazas, J. de Dios Ruiz-Rosado, S. A. Amici et al., "Helminth-induced Ly6 $\mathrm{C}^{\text {hi }}$ monocyte-derived alternatively activated macrophages suppress experimental autoimmune encephalomyelitis," Scientific Reports, vol. 7, article 40814, 2017.

[111] L. I. Terrazas, D. Montero, C. A. Terrazas, J. L. Reyes, and M. Rodríguez-Sosa, "Role of the programmed Death-1 pathway in the suppressive activity of alternatively activated macrophages in experimental cysticercosis," International Journal for Parasitology, vol. 35, no. 13, pp. 1349-1358, 2005.

[112] J. L. Reyes, C. A. Terrazas, J. Alonso-Trujillo, N. van Rooijen, A. R. Satoskar, and L. I. Terrazas, "Early removal of alternatively activated macrophages leads to Taenia crassiceps cysticercosis clearance in vivo," International Journal for Parasitology, vol. 40, no. 6, pp. 731-742, 2010.

[113] C. Togno-Peirce, K. Nava-Castro, L. I. Terrazas, and J. Morales-Montor, "Sex-associated expression of costimulatory molecules CD80, CD86, and accessory molecules, PDL-1, PDL-2 and MHC-II, in F480+ macrophages during murine cysticercosis," BioMed Research International, vol. 2013, Article ID 570158, 9 pages, 2013.

[114] D. Hashimoto, A. Chow, C. Noizat et al., "Tissue-resident macrophages self-maintain locally throughout adult life with minimal contribution from circulating monocytes," Immunity, vol. 38, no. 4, pp. 792-804, 2013.

[115] C. Schulz, E. G. Perdiguero, L. Chorro et al., "A lineage of myeloid cells independent of Myb and hematopoietic stem cells," Science, vol. 336, no. 6077, pp. 86-90, 2012.

[116] C. C. Bain, C. A. Hawley, H. Garner et al., "Long-lived selfrenewing bone marrow-derived macrophages displace embryo-derived cells to inhabit adult serous cavities," Nature Communications, vol. 7, 2016.

[117] S. M. Campbell, J. A. Knipper, D. Ruckerl et al., "Myeloid cell recruitment versus local proliferation differentiates susceptibility from resistance to filarial infection," Elife, vol. 7, article e30947, 2018.

[118] F. Ginhoux and M. Guilliams, "Tissue-resident macrophage ontogeny and homeostasis," Immunity, vol. 44, no. 3, pp. 439-449, 2016.

[119] C. L. Scott, F. Zheng, P. de Baetselier et al., "Bone marrowderived monocytes give rise to self-renewing and fully differentiated Kupffer cells," Nature Communications, vol. 7, article 10321, 2016.

[120] S. J. Jenkins, D. Ruckerl, P. C. Cook et al., "Local macrophage proliferation, rather than recruitment from the blood, is a signature of $\mathrm{T}_{\mathrm{H}} 2$ inflammation," Science, vol. 332, no. 6035, pp. 1284-1288, 2011.

[121] S. J. Jenkins, D. Ruckerl, G. D. Thomas et al., "IL-4 directly signals tissue-resident macrophages to proliferate beyond homeostatic levels controlled by CSF-1," The Journal of Experimental Medicine, vol. 210, no. 11, pp. 24772491, 2013.

[122] D. Ruckerl and J. E. Allen, "Macrophage proliferation, provenance, and plasticity in macroparasite infection," Immunological Reviews, vol. 262, no. 1, pp. 113-133, 2014.

[123] C. M. Minutti, L. H. Jackson-Jones, B. García-Fojeda et al., "Local amplifiers of IL-4R $\alpha$-mediated macrophage activation promote repair in lung and liver," Science, vol. 356, no. 6342, pp. 1076-1080, 2017.

[124] L. H. Jackson-Jones, D. Ruckerl, F. Svedberg et al., "IL-33 delivery induces serous cavity macrophage proliferation independent of interleukin-4 receptor alpha," European Journal of Immunology, vol. 46, no. 10, pp. 2311-2321, 2016. 
[125] U. M. Gundra, N. M. Girgis, D. Ruckerl et al., "Alternatively activated macrophages derived from monocytes and tissue macrophages are phenotypically and functionally distinct," Blood, vol. 123, no. 20, pp. e110-e122, 2014.

[126] A. V. Misharin, L. Morales-Nebreda, P. A. Reyfman et al., "Monocyte-derived alveolar macrophages drive lung fibrosis and persist in the lung over the life span," The Journal of Experimental Medicine, vol. 214, no. 8, pp. 2387-2404, 2017.

[127] U. M. Gundra, N. M. Girgis, M. A. Gonzalez et al., "Vitamin A mediates conversion of monocyte-derived macrophages into tissue-resident macrophages during alternative activation," Nature Immunology, vol. 18, no. 6, pp. 642-653, 2017.

[128] K. Takeda, T. Tanaka, W. Shi et al., "Essential role of Stat6 in IL-4 signalling,” Nature, vol. 380, no. 6575, pp. 627-630, 1996.

[129] G. Raes, L. Brys, B. K. Dahal et al., "Macrophage galactosetype C-type lectins as novel markers for alternatively activated macrophages elicited by parasitic infections and allergic airway inflammation," Journal of Leukocyte Biology, vol. 77, no. 3, pp. 321-327, 2005.

[130] I. van Die and R. D. Cummings, "The mannose receptor in regulation of helminth-mediated host immunity," Frontiers in Immunology, vol. 8, p. 1677, 2017.

[131] L. Martinez-Pomares, D. M. Reid, G. D. Brown et al., "Analysis of mannose receptor regulation by IL-4, IL-10, and proteolytic processing using novel monoclonal antibodies," Journal of Leukocyte Biology, vol. 73, no. 5, pp. 604-613, 2003.

[132] S. A. Linehan, P. S. Coulson, R. A. Wilson et al., "IL-4 receptor signaling is required for mannose receptor expression by macrophages recruited to granulomata but not resident cells in mice infected with Schistosoma mansoni," Laboratory Investigation, vol. 83, no. 8, pp. 1223-1231, 2003.

[133] R. A. Paveley, S. A. Aynsley, J. D. Turner et al., "The mannose receptor (CD206) is an important pattern recognition receptor (PRR) in the detection of the infective stage of the helminth Schistosoma mansoni and modulates IFN $\gamma$ production," International Journal for Parasitology, vol. 41, no. 13-14, pp. 1335-1345, 2011.

[134] E. van Liempt, C. M. C. Bank, P. Mehta et al., "Specificity of DC-SIGN for mannose- and fucose-containing glycans," FEBS Letters, vol. 580, no. 26, pp. 6123-6131, 2006.

[135] B. Everts, G. Perona-Wright, H. H. Smits et al., "Omega-1, a glycoprotein secreted by Schistosoma mansoni eggs, drives Th2 responses," The Journal of Experimental Medicine, vol. 206, no. 8, pp. 1673-1680, 2009.

[136] S. Steinfelder, J. F. Andersen, J. L. Cannons et al., “The major component in schistosome eggs responsible for conditioning dendritic cells for Th2 polarization is a T2 ribonuclease (omega-1)," The Journal of Experimental Medicine, vol. 206, no. 8, pp. 1681-1690, 2009.

[137] B. Everts, L. Hussaarts, N. N. Driessen et al., "Schistosomederived omega-1 drives Th2 polarization by suppressing protein synthesis following internalization by the mannose receptor," The Journal of Experimental Medicine, vol. 209, no. 10, pp. 1753-1767, 2012.

[138] A. Gruden-Movsesijan and L. S. Milosavljevic, "The involvement of the macrophage mannose receptor in the innate immune response to infection with parasite Trichinella spiralis," Veterinary Immunology and Immunopathology, vol. 109, no. 1-2, pp. 57-67, 2006.
[139] M. L. deSchoolmeester, L. Martinez-Pomares, S. Gordon, and K. J. Else, "The mannose receptor binds Trichuris muris excretory/secretory proteins but is not essential for protective immunity," Immunology, vol. 126, no. 2, pp. 246-255, 2009.

[140] A. Aldridge and S. M. O'Neill, "Fasciola hepatica tegumental antigens induce anergic-like $\mathrm{T}$ cells via dendritic cells in a mannose receptor-dependent manner," European Journal of Immunology, vol. 46, no. 5, pp. 1180-1192, 2016.

[141] Y. Kumamoto, M. Linehan, J. S. Weinstein, B. J. Laidlaw, J. E. Craft, and A. Iwasaki, "CD301b ${ }^{+}$dermal dendritic cells drive T helper 2 cell-mediated immunity," Immunity, vol. 39, no. 4, pp. 733-743, 2013.

[142] E. Rodríguez, P. Carasi, S. Frigerio et al., "Fasciola hepatica immune regulates $\mathrm{CD} 11 \mathrm{c}^{+}$cells by interacting with the macrophage Gal/GalNAc lectin," Frontiers in Immunology, vol. 8, p. 264, 2017.

[143] B. Shook, E. Xiao, Y. Kumamoto, A. Iwasaki, and V. Horsley, "CD301 $\mathrm{b}^{+}$macrophages are essential for effective skin wound healing," The Journal of Investigative Dermatology, vol. 136, no. 9, pp. 1885-1891, 2016.

[144] D. R. Herbert, T. Orekov, A. Roloson et al., "Arginase I suppresses IL-12/IL-23p40-driven intestinal inflammation during acute schistosomiasis," The Journal of Immunology, vol. 184, no. 11, pp. 6438-6446, 2010.

[145] L. A. Borthwick, L. Barron, K. M. Hart et al., "Macrophages are critical to the maintenance of IL-13-dependent lung inflammation and fibrosis," Mucosal immunology, vol. 9, no. 1, pp. 38-55, 2016.

[146] L. Barron, A. M. Smith, K. C. El Kasmi et al., "Role of arginase 1 from myeloid cells in th2-dominated lung inflammation," PLoS One, vol. 8, no. 4, article e61961, 2013.

[147] C. G. Lee, C. A. Da Silva, C. S. Dela Cruz et al., "Role of chitin and chitinase/chitinase-like proteins in inflammation, tissue remodeling, and injury," Annual Review of Physiology, vol. 73, no. 1, pp. 479-501, 2011.

[148] M. G. Nair, I. J. Gallagher, M. D. Taylor et al., "Chitinase and fizz family members are a generalized feature of nematode infection with selective upregulation of Ym1 and Fizz1 by antigen-presenting cells," Infection and Immunity, vol. 73, no. 1, pp. 385-394, 2004.

[149] K. M. Vannella, T. R. Ramalingam, K. M. Hart et al., “Acidic chitinase primes the protective immune response to gastrointestinal nematodes," Nature Immunology, vol. 17, no. 5, pp. 538-544, 2016.

[150] M. Owhashi, H. Arita, and N. Hayai, "Identification of a novel eosinophil chemotactic cytokine (ECF-L) as a chitinase family protein," The Journal of Biological Chemistry, vol. 275, no. 2, pp. 1279-1286, 2000.

[151] T. E. Sutherland, N. Logan, D. Ruckerl et al., "Chitinase-like proteins promote IL-17-mediated neutrophilia in a tradeoff between nematode killing and host damage," Nature Immunology, vol. 15, no. 12, pp. 1116-1125, 2014.

[152] W. G. C. Horsnell and B. G. Dewals, "RELMs in the realm of helminths," Trends in Parasitology, vol. 32, no. 7, pp. 512514, 2016.

[153] J. C. Jang and M. G. Nair, "Alternatively activated macrophages revisited: new insights into the regulation of immunity, inflammation and metabolic function following parasite infection," Current Immunology Reviews, vol. 9, no. 3, pp. 147-156, 2013. 
[154] M. G. Nair, Y. Du, J. G. Perrigoue et al., “Alternatively activated macrophage-derived RELM- $\alpha$ is a negative regulator of type 2 inflammation in the lung," The Journal of Experimental Medicine, vol. 206, no. 4, pp. 937-952, 2009.

[155] G. Chen, S. H. Wang, J. C. Jang, J. I. Odegaard, and M. G. Nair, "Comparison of RELM $\alpha$ and RELM $\beta$ single- and double-gene-deficient mice reveals that RELM $\alpha$ expression dictates inflammation and worm expulsion in hookworm infection," Infection and Immunity, vol. 84, no. 4, pp. 11001111, 2016.

[156] T. Liu, H. Jin, M. Ullenbruch et al., "Regulation of found in inflammatory zone 1 expression in bleomycin-induced lung fibrosis: role of IL-4/IL-13 and mediation via STAT-6," Journal of Immunology, vol. 173, no. 5, pp. 3425-3431, 2004.

[157] J. A. Knipper, S. Willenborg, J. Brinckmann et al., "Interleukin-4 receptor $\alpha$ signaling in myeloid cells controls collagen fibril assembly in skin repair," Immunity, vol. 43, no. 4, pp. 803-816, 2015.

[158] P. Loke and J. P. Allison, "PD-L1 and PD-L2 are differentially regulated by Th1 and Th2 cells," Proceedings of the National Academy of Sciences of the United States of America, vol. 100, no. 9, pp. 5336-5341, 2003.

[159] S. Huber, R. Hoffmann, F. Muskens, and D. Voehringer, "Alternatively activated macrophages inhibit T-cell proliferation by Stat6-dependent expression of PD-L2," Blood, vol. 116, no. 17, pp. 3311-3320, 2010.

[160] C. L. Fu, J. I. Odegaard, and M. H. Hsieh, "Macrophages are required for host survival in experimental urogenital schistosomiasis," The FASEB Journal, vol. 29, no. 1, pp. 193-207, 2015.

[161] R. S. Longman, G. E. Diehl, D. A. Victorio et al., " $\mathrm{CX}_{3} \mathrm{CR} 1^{+}$ mononuclear phagocytes support colitis-associated innate lymphoid cell production of IL-22," The Journal of Experimental Medicine, vol. 211, no. 8, pp. 1571-1583, 2014.

[162] P. Gupta, S. M. Lai, J. Sheng et al., "Tissue-Resident CD169 macrophages form a crucial front line against plasmodium infection," The Journal of Experimental Medicine, vol. 16, no. 6, pp. 1749-1761, 2016.

[163] M. Mack, J. Cihak, C. Simonis et al., "Expression and characterization of the chemokine receptors CCR2 and CCR5 in mice," The Journal of Immunology, vol. 166, no. 7, pp. 4697-4704, 2001. 


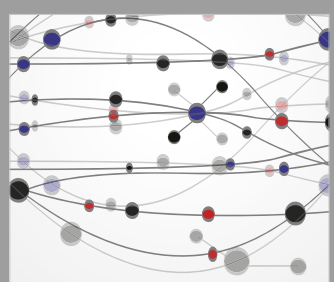

The Scientific World Journal
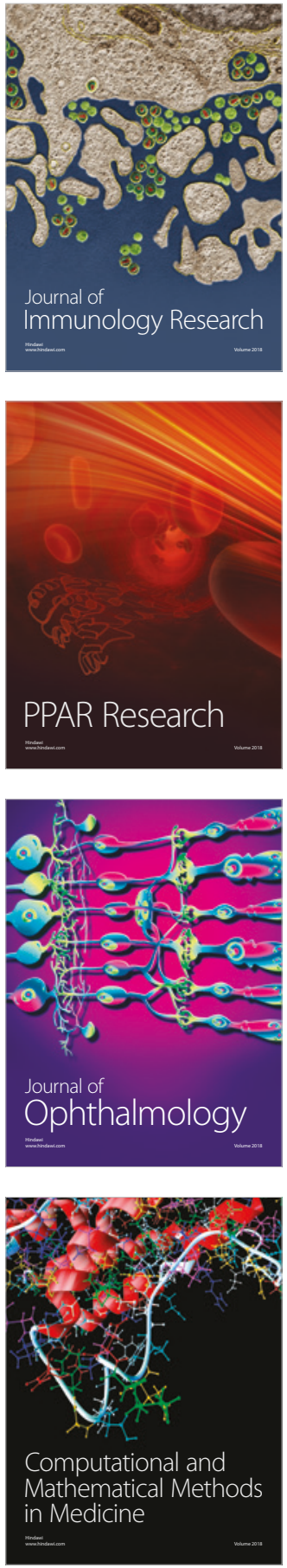

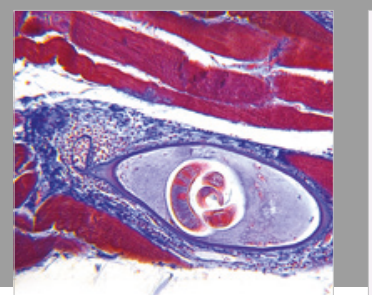

Gastroenterology Research and Practice

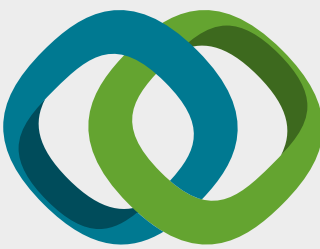

\section{Hindawi}

Submit your manuscripts at

www.hindawi.com
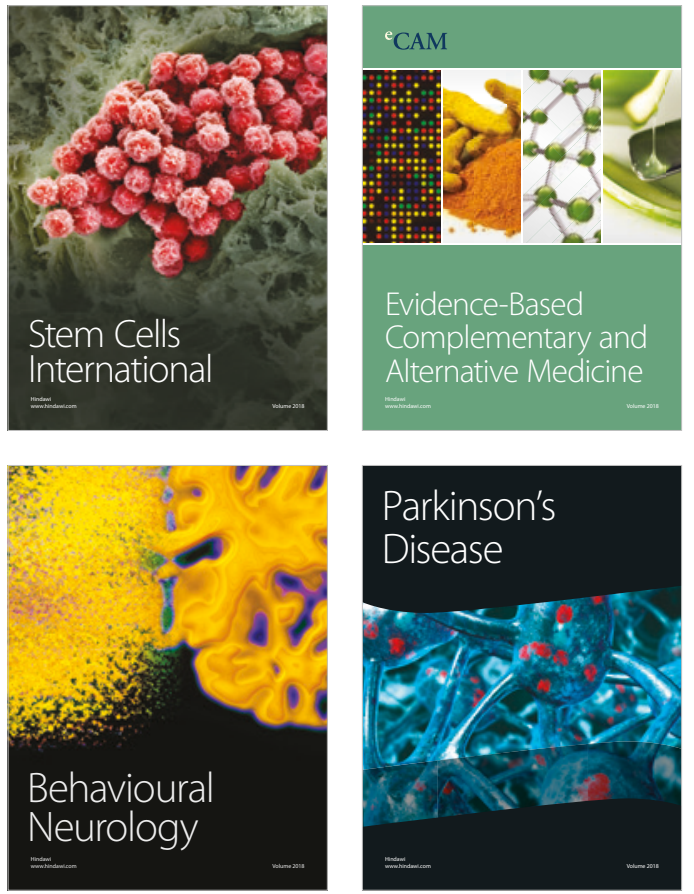

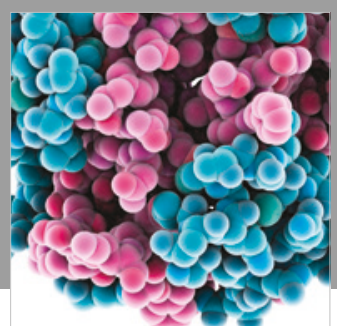

ournal of

Diabetes Research

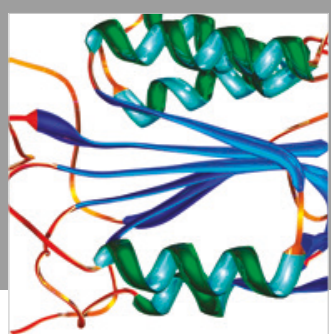

Disease Markers
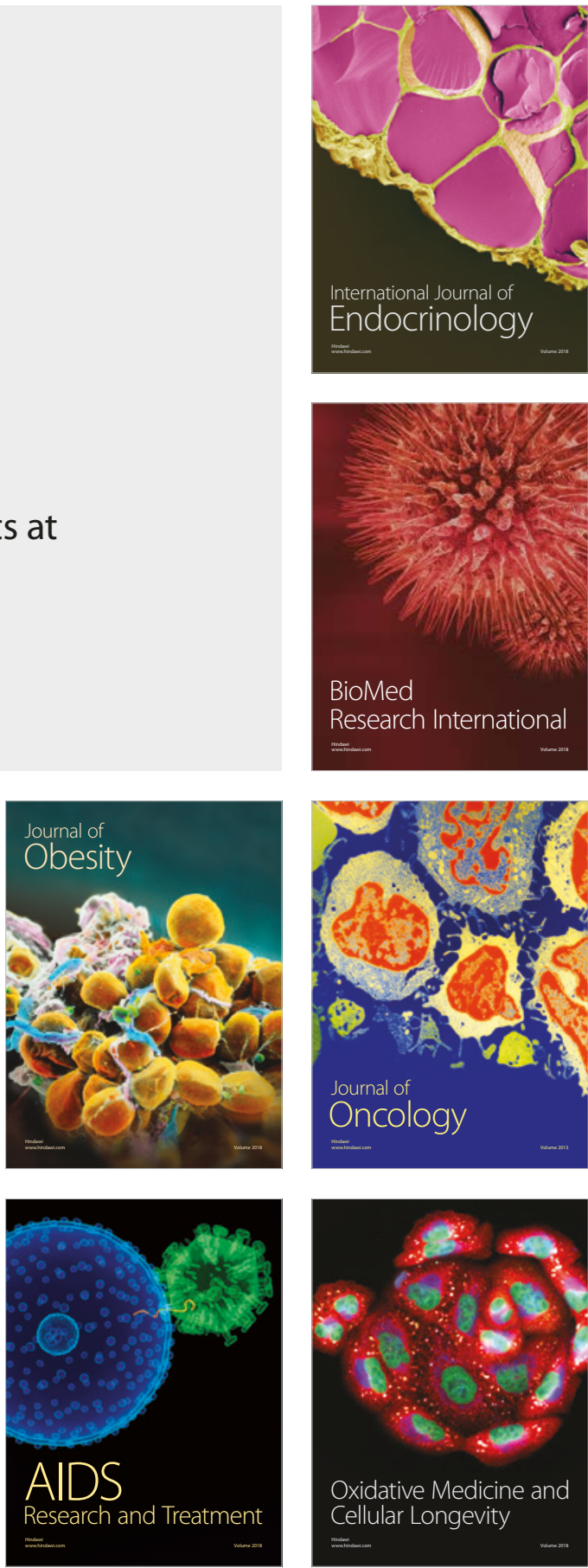